\title{
Sustainable maritime inventory routing problem with time window constraints
}

\author{
Arijit De ${ }^{\mathrm{a}, 1}$, Sri Krishna Kumar ${ }^{\mathrm{a}, 2}$, Angappa Gunasekaran ${ }^{\mathrm{b}}$, Manoj Kumar Tiwari ${ }^{* a, 3}$ \\ ${ }^{a}$ Department of Industrial and Systems Engineering, Indian Institute of Technology \\ Kharagpur, Kharagpur 721 302, West Bengal, India \\ ${ }^{b}$ Department of Decision and Information Sciences, University of Massachusetts, Dartmouth, \\ 285 Old Westport Road, North Dartmouth, MA 02748-1778, USA
}

\begin{abstract}
Maritime inventory routing problem is addressed in this paper to satisfy the demand at different ports during the planning horizon. It explores the possibilities of integrating slow steaming policy as mentioned in Kontovas et al. 2011 and Norstad et al. 2011 within ship routing. A mixed integer nonlinear programming model is presented considering various scheduling and routing constraints, loading/unloading constraints and vessel capacity constraints. Non-linear equation between fuel consumption and vessel speed has been incorporated to capture the sustainability aspects. Several time window constraints are inculcated in the mathematical model to enhance the service level at each port. Penalty costs are incurred if the ship arrives early before the starting of the time window or if it finishes its operation after the ending of the time window. Costs associated with the violation of time window helps in maintaining a proper port discipline. Now, owing to the inherent complexity of the aforementioned problem, an effective search heuristics named Particle Swarm Optimization for Composite Particle (PSO-CP) is employed. Particle Swarm Optimization - Differential Evolution (PSO-DE), Basic PSO and Genetic Algorithm (GA) are used to validate the result obtained from PSO-CP. Computational results provided for different problem instances shows the superiority of PSO-CP over the other algorithms in terms of the solution obtained.
\end{abstract}

Keywords: Ship routing and scheduling, Maritime transportation, Mixed integer non-linear programming, Maritime inventory routing, Slow steaming, Fuel consumption, Particle swarm optimization for composite particle

\section{INTRODUCTION}

Maritime logistics sector is considered to be the most important mode of transportation involving 9.6 billion tons of world trade in 2013 as reported in UNCTAD 2014. Maritime transportation comprises of around $80 \%$ of the international trade as mentioned in UNCTAD, 2013. It is estimated that around $65 \%$ to $85 \%$ of total global trade is carried using seaborne shipping as mentioned in Christiansen et al. 2007. Volume of the global seaborne shipments expanded by $3.4 \%$ in 2014 as reported in UNCTAD 2015. Containerized trade contributes about $15 \%$ share to the international seaborne trade. Containerized trade volume is estimated to have increased by $5.3 \%$ in 2014, taking the total to 1.63 billion tons. Increasing level of international trade using sea-route has led to greater attention in the domain of ship routing and scheduling. In this paper, a particular ship routing and scheduling problem is studied considering the aspects of containerized trade. Although it is observed that maritime transportation leads to a significant consumption of fuel. Hence, it is essential to achieve greater sustainability by considering several environmental friendly policies such as slow steaming, speed optimization, fuel efficient vessels etc. 
International shipping emitted around $2.7 \%$ of carbon di oxide in 2007 on the basis of $2^{\text {nd }}$ International Maritime Organisation (IMO) GHG Study 2009 as mentioned in Buhaug et al. 2009. ICS 2009 addressed the issue of green-house gas emissions in maritime transportation and estimated that short-sea shipping contributes around $25 \%$ of GHG emissions. Furthermore, this percentage may drastically increase if no possible measures are adopted to curb the emissions. In recent years, environmental issues pertaining to seaborne shipping and increasing fuel prices have given vessel speed a newer perspective. As stated in UNCTAD 2015, practice of speed optimization in container shipping helps to counter high fuel prices. Ship speed has a non-linear relationship with fuel consumption as mentioned in Norstad et al. 2011. Therefore, speed optimization or ideally slow steaming can be implemented as an operational measure to depict the amount of fuel consumed. The research work presented in this paper addresses the sustainability aspects in maritime transportation by considering vessel speed optimization strategy. Slow steaming policy has been adopted to estimate the total amount of fuel consumed in sea and port. Fuel cost incurred in sea is computed using the relationship between vessel speed and fuel consumption.

Maritime transportation faces different challenges of lowering the fuel consumption and minimizing the transportation cost. Also increased amount of maritime traffic volume requires efficient routing and scheduling of ships. Container shipping is concerned with the distribution of multiple containers of different types from one port to another using a heterogeneous fleet of ships. Each port has its storage capacity or demand on the basis of whether it is a production or consumption port. Designing the schedules and routes for the fleet of ships on the basis of number of containers to be loaded or unloaded is an important aspect to be taken into account. Reducing the total transportation cost for each vessel without interrupting the supply and demand remains one of the primary challenges. The work presented in the paper performs efficient routing and scheduling of vessels such that the demand and supply of containerised cargo could be met at different ports.

There is an increasing interest to explore the possible ways for improving the service level at port. The issue pertaining to the time spent by a ship at a port can be addressed by considering a time window concept. Each ship should carry out its loading/unloading operations within the time window of the port. Violation of time window takes place when the ship finishes its operation outside the specified time window. Furthermore, the vessel can arrive much before the starting of the time window. In such a situation, it will remain idle till the beginning of the time window. There are different challenges encountered in implementing the time window concept in a port. Several measures need to be taken in order to counter the scenarios of early arrival of a ship as well as violation of the time window. The paper incorporates time window concept to enhance the service level at the port. Multiple vessels arriving before the allotted time window range may lead to congestion at the port. Such scenarios are countered in this paper by imposing penalty cost per hour of waiting before the starting of the time window. Certain vessels may fail to finish its operation within the allotted time window range, thereby incurring penalty charges per hour as considered in the paper.

Now, a shipping company generally operates on heterogeneous fleet of vessels having different carrying capacities, speeds, physical dimensions and operating costs. The ship transports multiple types of containers from production ports to consumption ports and ensures a check in the capacity of the port. The challenge lies in determining the ideal distribution policies such that scheduling and operating costs are minimized. Simultaneously, it is essential to keep a track on the ship's inventory and port's capacity for maintaining it within a certain limit. Proper inventory management decisions are important in the context of maritime transportation as it can be beneficial for port operations. The objective of the paper is to elaborately study a sustainable maritime inventory problem considering different shipping operations such as ship routing and scheduling, time window concept at ports, 
multiple ships operating at a port due to the presence of number of available berths, loading unloading operations at port, speed optimization strategy for computing the fuel consumed by the ship. In view of the objective of the paper, a novel mathematical model addressing sustainable maritime inventory routing problem is presented aiming to minimize the fuel cost of the shipping company and penalty charges associated with the violation of the time window, docking cost and variable cost pertaining to the loading and unloading operation at the port.

The contributions made in this paper are of interest for other researchers working in the domain of sustainable maritime transportation. The novelty of the paper lies in integrating different maritime operations such as ship routing and scheduling, loading/unloading of containers at ports, time window concept considering penalty costs to deal with violation and fuel consumption associated with different vessels. De et al. 2016 considered different shipping operation and presented a generic mathematical model for a sustainable ship routing and scheduling problem. They primarily focussed on transportation cost, set up cost and penalty cost associated with the violation of time window in their objective function and overlooked the fuel cost at port and sea as well as variable cost at the port depending upon the number of containers loaded/unloaded. A robust mathematical formulation developed in this research work aims to minimize the total cost of the container shipping company considering fuel cost at port and sea, fixed and variable cost at port and different penalty cost for violating the time window. The model incorporates slow steaming strategy to estimate the fuel consumption at sea, routing constraints, time window constraints and ship's capacity related constraints. Time window constraints improves the service level at the port by imposing penalty cost for two different scenarios of vessel arriving early before the starting of the time window and the vessel finishing its operation outside the specified time window. As slow steaming policy increases the total voyage time of a ship, hence it is essential to consider time window concept in the model for keeping a check on the arrival and departure time of the vessel. Fixed cost associated with performing a loading/unloading operation at a port and variable cost related to the number of containers loaded/unloaded are considered in the model to compute the overall operation cost of a vessel. Predominantly, Heavy Fuel Oil (HFO) is employed to run the ship's main engine while sailing in sea and at port Marine Diesel Oil (MDO) is used to run vessel's auxiliary engine. The fuel consumption for each vessel is computed keeping this practicality in mind and corresponding average fuel prices considered are 463.50 USD/ton and 586 USD/ton for HFO and MDO respectively (Kontovas et al. 2011). Fuel prices generally keep fluctuating with time but for computational experiment it is assumed to be constant in this paper. The study successfully integrates speed optimization policy along with fuel prices to estimate the total fuel cost and address the sustainability aspects in maritime transportation domain. Fuel cost incurred at a port is computed by taking into account the total operating time and the fuel consumed by the vessel at a port per hour. Moreover, the model considers the simultaneous operation of multiple numbers of ships in a period as in practicality each port contains numerous berths.

The rest of the paper is organized in following manner: Section 2 provides a brief literature review on relevant studies related ship routing and scheduling problem. In Section 3, the problem environment is discussed in an elaborate manner. In Section 4, the mathematical formulation and the descriptions of the objective function and constraints are presented. The proposed solution approach for the problem is mentioned in section 5. The implementation of particle swarm optimization for composite particle (PSO-CP) algorithm is illustrated over here. Section 6 is devoted to the results and discussions of the extensive computational study carried out. Conclusions are given in section 7. It also includes the managerial implications and future scope of the problem. 


\section{LITERATURE REVIEW}

Maritime inventory routing problems involves transportation of several products between different ports and constant monitoring of the inventory level for all the products at the ports. This section provides a brief review on the relevant studies in the domain of basic maritime inventory routing problem (MIRP). Christiansen et al. 1998 dealt with a MIRP for routing several vessels and performing the inventory management at different ports. Their model comprises of inventory pick-up and delivery of a single product to different ports using a fleet of ships for short-term planning horizon. Christiansen et al. 1999 examined a maritime transportation problem of a single product (ammonia) between several production and consumption facilities. The product is produced and stored in inventory facilities and later transported using a fleet of ships to several ports. The aim of this problem is to design appropriate shipping routes and schedules for minimizing the total costs associated with transportation without interruption of operations at the storages. Although, the vessel sailing time considered as constant in their formulation could be relaxed as per the realistic scenario. In subsequent years several articles are reported considering both inventory and routing taken into account. Ronen 2002 investigated a maritime inventory routing problem considering multiple products and presented a mathematical model also capturing the intricacies of inventory management at the port. The time window concept is ignored in their model that may affect its real life application. An optimization approach developed by Bilgen et al. 2007 addressing a problem involving the supply of bulk grain products from one loading port to another consumption port using a fleet of ships. The approach aims to minimize the total cost, including the blending, loading, transportation and inventory costs. Other researcher such as Dauzère-Pérès et al. 2007 dealt with real-life maritime inventory routing problem for a Norwegian company Omya Hustadmarmor and developed a decision support system on the basis of an optimization model. Their approach saved the production and transportation costs close to around US\$7 million a year for the company. The subsequent sections deal with models associated to complex maritime inventory routing problems, time window concept and slow steaming policy.

\subsection{COMPLEX MARITIME INVENTORY ROUTING MODELS}

Within the domain of maritime transportation, an increased interest is observed among researcher to adopt advanced optimization approach for solving maritime inventory routing problems. Fodstad et al. 2010 presented a decision support system pertaining to a Liquified Natural Gas (LNG) supply chain optimization model integrating ship routing problem along with inventory management. The focus of the paper lies in maximizing the profit by considering different trading contracts. In LNG business, Grønhaug et al. 2010 dealt with a maritime inventory routing problem considering vessel routing for special purpose ships. Mixed integer programming models depicting ship route planning and inventory management for LNG supply chain were presented by Andersson et al. 2010. Time window concept is overlooked in the aforementioned papers which can be a possible scope of improvement. A continuous time mixed integer linear programming (MILP) model addressing a maritime logistics problem associated with global chemical companies for maintaining the inventory levels at various ports is observed in Li et al. 2010. Voyage time of the ship from one port to another is assumed to be constant in their paper, but in reality sailing time keeps varying as it depends upon the vessel speed. Andersson 2011 tried to resolve the intricacies associated with maritime pulp distribution problem by modelling a mixed integer linear programming model and employing branch and price method for solving purpose. This model generates schedules for vessels sailing from different ports to the customers as well as direct deliveries from the pulp mills to the ports. 
In recent years, several researchers addressed maritime inventory routing problem and presented different advanced models focussing on routing and scheduling of ships as well as different port operations. Christiansen et al. 2011 addressed a ship routing and scheduling problem along with the inventory management of multiple non-mixable products for a cement company and employed a construction heuristic approach for solving purpose. Different ideas pertaining to variable demand and supply rates of the products, service speed of the vessel, fuel consumption rates (for sailing and also while being idle) are mentioned, yet no mathematical equation are presented in the paper depicting the same. Other researchers such as Furman et al. 2011 developed a decision support system on the basis of a mixed-integer programming model depicting a real-world ship routing problem for improving the performance of a petroleum and natural gas company named ExxonMobil. A single product vacuum gas oil (VGO) routing problem between several ports is considered in their paper which can be extended to multiple product case. Some of the researchers such as Shen et al. 2011 and Rocha et al. 2013 focussed on a similar type of problem pertaining to maritime inventory routing associated with the transportation of crude oil via heterogeneous fleet of ships. Transportation of crude oil using multiple types of tankers includes several supply ports, transhipments harbours with limited inventory capacities and customer ports. Multiple product case is again ignored in the research works which can be a possible scope of expansion. Engineer et al. 2012 dealt with a single product vessel routing problem for a planning horizon considering different supply and demand rates at facilities as well as varying storage capacities at ports. Demurrage charges and draft restrictions are incorporated in their model to address the realistic scenario. The model can be extended by considering other practical considerations such as multiple product case and time window range at port. Goel et al. 2012 and Uggen et al. 2013 addressed maritime inventory routing problem for a Liquefied Natural Gas (LNG) and developed respective mathematical models to determine an optimal schedule for all the ships by specifying the fleet composition and size, terminal storage capacities and berth facilities. Travel time is considered as a parameter in both the model, although in practicality voyage time keeps changing depending upon the speed of the vessel. Other researchers such as Agra et al. 2013a and Papageorgiou et al. 2014a extensively studied ship routing and scheduling problem for a planning horizon and integrated inventory management within the problem for addressing varying supply and demand rates at ports. Each of the respective problem deals with routing of a heterogeneous fleet of ships between multiple ports with limited storage capacity and carrying out loading/unloading operations at ports. The models developed in the aforementioned research works overlooked the penalty costs associated with ship remaining idle or waiting charges before the starting of the time window. Travelling time of the vessel between different ports is assumed to be constant in the models which can be considered as a decision variable to make it realistic in nature. Hewitt et al. 2013 dealt with a complex problem of single product transportation to multiple sites using a fleet of ships. They focussed on a real-world maritime inventory routing problem capturing the various aspects of ship routing. Variable cost associated with the number of products loaded/unloaded at the port can also be added in their model for addressing service level related costs. Papageorgiou et al. 2014b addressed a single product maritime inventory routing problem which can be extended to a multiple product case as observed in the practical scenarios. Moreover, it is essential to consider fuel cost as one of the component in the objective function as it entirely determines the transportation cost of the vessel. They developed two decomposition algorithms to show the superiority over commercial solvers in terms of computational efficiency. 


\subsection{MODELS WITH TIME WINDOWS CONCEPT}

Each port has a specific time window range for providing service in terms of loading/unloading of containers from the vessel. Some of the researcher have considered time window concept in their work to reduce the delay in providing the service at the port. Al-khayyal et al. 2007 developed a mathematical model focussing on a maritime inventory routing problem considering the concept of time window. They assumed different compartments in the ship for storing multiple types of products. Penalty costs are considered in their work to deal with the violation pertaining to the time window. More robust ship schedules can be designed by the introduction of penalties pertaining to waiting time for avoiding the vessel idle times. Their model considered an assumption that only a single vessel can operate at a port in a time period, whereas in reality multiple ships carry out their respective operation in a period depending upon the number of berths available. Siswanto et al. 2011 studied a similar type of problem in the context of multiple products stored in undedicated compartments of the ship. Their model considers time window range for performing the loading and unloading operation at the ports. The problem aims to minimize the transportation costs and operational cost by focussing on three aspects - vessel selection, route optimization and loading/unloading operation. The problem includes the transportation of non-mixable products from one port to another using heterogeneous fleet of ships. Agra et al. 2015 dealt with a short sea shipping problem in the context of maritime inventory routing of oil products between different ports. Although, all the aforementioned papers dealt with ship routing problem with known sailing time and service time, they do consider uncertain travelling time and measures to cope with port waiting times. It is essential to address ways to counter uncertain waiting times of the vessel before the start of service for reducing port congestion. Song et al. 2013 proposed a new time-space network formulation accommodating several practical features such as time window concept in the context of maritime inventory routing problem. Demurrage costs are considered in the model when the overall loading/unloading time exceeds the lay-time or the time operated at port. Although, travelling time is assumed to constant in their model, but in practicality travel time between ports keeps changing as it depends on vessel speed, weather conditions etc. Agra et al. $2013 \mathrm{~b}$ dealt with short sea ship routing problem aiming to supply products from loading ports to unloading port via multiple vessels. The provision of time window is considered at different port to handle uncertainties associated with port time. A real-world problem of an oil company is presented focussing on designing the routes and schedules of vessels for meeting the demand of fuel oil products at different ports. Hemmati et al. 2016 studied a maritime inventory routing problem for transporting multiple-product using heterogeneous fleet of ships. Time window model is solved to generate feasible time window ranges for performing the loading/unloading operations at different port. Agra et al. 2014 examined a short sea inventory routing problem and accordingly presented a mathematical model considering several real time constraints associated with the time window concept. Armas et al. 2015 dealt with a ship routing and scheduling problem and considered discretized time windows as it allows the flexibility to incorporate practical constraints in a simpler way.

\subsection{MODELS CONSIDERING SLOW STEAMING POLICY}

It is well described in the literature about the non-linear relationship between fuel consumption and vessel speed. Minimizing the vessel fuel cost is a key factor in maritime transportation domain, as it accounts for more than $50 \%$ of the total operating costs as mentioned in Fagerholt et al. 2015. Hence, several researchers have considered the slow steaming policy in ship routing models to reduce the emissions of greenhouse gases and shipping's impact on the environment. Norstad et al. 2011 dealt with a vessel routing problem and developed a formulation considering slow steaming policy, time 
window and vessel capacity constraints and introducing ship speed as a decision variable. Other complex port operations such as loading/unloading operation and inventory management at port are overlooked in their paper. It is observed in their work that slow steaming strategy enables vessels to sail at economic speeds leading to cutting down of the fuel consumption costs. Disadvantages associated with slow steaming are deployment of additional vessels to maintain the service level of the shipping company. Ronen 2011 extensively studied about the effect of slow steaming may increase the number of extra vessels on each route. The main deliverables of their model are sailing speed of each ship, total operating cost incurred and number of vessels required. In certain cases, incorporating the slow steaming policy not only mitigates the fuel cost savings, it also increases the chartering cost. Psaraftis et al. 2010 studied about the trade-offs between reduction in vessel speed and change in the number of ships in the fleet. They discussed about the impact of speed reduction entails to reconfigure the ship engine so as to perform better under a reduced load. They stressed upon the need for building ships with smaller engines, efficient vessel hulls and modifying propeller designs for long-term implementation of slow steaming policy. Thus, it is worthwhile to adopt vessel speed reduction strategy if the savings in fuel cost exceeds the charter cost or fixed cost for hiring additional vessels. Other researchers such as Meng et al. 2011 and Wang et al. 2012a also incorporated service frequency, deployment of ships and vessel speed in their formulation and presented a Mixed Integer Non-Linear Programming (MINLP) models. They stated that shipping companies consider slow steaming strategy only during the high bunker price scenario and availability of large number of container ships. Psaraftis et al. 2013 stated about the implementation of slow steaming leads to adjustment of the transit time, which in turn should not cause major interruption in meeting the demand at different ports. In fact, speed reduction provides essential buffer time to absorb delays due to unforeseen events. Most of the existing studies on slow steaming policy dealt with different optimization models considering the vessel speed relationship and determining the routes for the ships (Wang et al. 2012a, Fagerholt et al. 2015, Andersson et al. 2015). The mathematical models developed in aforementioned mentioned papers focussed on minimizing the fuel costs as it comprises of a major cost component in most of the maritime operations. Some of the researcher dealt with ship routing and scheduling problem considering the uncertainties in port operations and developed a MINLP model aiming to minimize the total fuel cost under stochastic condition considering the slow steaming policy (Wang et al. 2012b, Wang et al. 2012c). The optimality condition for the vessel speed function with respect to fuel consumption is presented in the aforementioned papers. Majority of the researchers have solved their respective mathematical model using non-distributed methods. Solving such complex mathematical formulations observed in the domain of maritime inventory routing using distributed methods can help the shipping companies to obtain feasible results in very less computational time. Hence, distributed methods can be adopted in future researches for resolving such complicated optimization problems.

Several researcher have done extensive research work on ship routing and scheduling such as Stalhane et al. 2012, Agra et al. 2013b, Agra et al. 2014 and Armas et al. 2015, yet they didn't address the intricacies associated with sustainability in maritime transportation domain. De et al. 2016 considered sustainability aspects in its mathematical model, yet overlooked the impact of fuel cost on the total transportation cost. The current research work aims to bridge this research gap by analysing the effect of fuel cost on the total cost of the shipping company. Siswanto et al. 2011, Agra et al. 2013b, Engineer et al. 2012 and De et al. 2016 considered time window concept in their model and focussed on improving the service level at the port by penalizing the violation when the vessel fails to finish its operation within the allotted time window range. Most of the earlier researches including the work of De et al. overlooked the need to penalize vessels for early arrival at the port as it increases congestion. The research work carried out in the paper includes the scenario of vessels arriving before 
the starting of the time window at a port. Multiple vessels arriving before the starting of the time window leads to port congestion as all the vessels have to wait before starting their respective loading/unloading operations. The contribution presented in this paper aims to address this issue by imposing penalty cost on the vessel for waiting before the starting of the time window. Earlier research works of Agra et al. 2013 and De et al. 2016 have simplified their respective mathematical models by ignoring the berthing capacity of a port as it considered only one vessel arrives at a port in a given time period to perform its port operation. The research work presented in this paper addressed this issue and incorporated the realistic scenario of multiple vessels arriving at a port in a given time period depending upon the number of berths available at the port. Most of the research work pertaining to maritime inventory routing only considered the combination of voyage cost and operation cost as the main objective function such as Al-khayyal et al. 2007, Agra et al. 2013, Engineer et al. 2012, Rocha et al. 2013 and De et al. 2016 have not taken into account the impact of fuel cost on the total cost. Transportation cost largely comprises of the fuel cost of the vessel which in turn can be reduced by incorporating slow steaming strategy. Hennig et al. 2012 presented a maritime inventory routing problem considering the fuel cost when the vessel operates at a port but overlooked vessel's fuel consumption in sea. Norstad et al. 2011, Andersson et al. 2015 and Yao et al. 2012 developed different ship routing models considering slow steaming strategy to compute the fuel consumption. Earlier researches primarily addressed ship routing and scheduling or entirely on vessel fuel consumption considering slow steaming strategy. Few researches such as Andersson et al. 2015 and Yao et al. 2012 incorporated the vessel speed optimization to address sustainability aspects in ship routing but fail to apprehend other complex shipping operations such as loading/unloading of containers, time window concept. The relationship between ending time of operation, sailing speed and vessel arrival time is incorporated in this paper which has been overlooked in majority of the earlier research work such as Norstad et al. 2011, Yao et al. 2012, Andersson et al. 2015 and De et al. 2016. The contribution presented in the paper aims to bridge the aforementioned research gaps by developing an optimization approach addressing the maritime operations such as ship routing and scheduling, loading/unloading of containers at port, time window concept, vessel speed optimization for estimating the fuel consumed and meeting the demand at different ports. A Mixed Integer NonLinear Programming (MINLP) model is developed considering all the shipping operations mentioned earlier.

\section{PROBLEM DESCRIPTION}

Maritime inventory routing problem (MIRP) is considered with an aim to meet the demand at several ports. The main characteristic of a MIRP lies in designing the routes and schedules of a fleet of ships within an appropriate planning horizon. Each ship starts from an initial port position at the starting of the planning horizon and sails from one port to another carrying certain numbers of the containers. The planning horizon considered for a maritime inventory routing problem is discretized into set of time periods corresponding to days. A vessel visits several ports in different periods within the overall planning horizon for performing the loading/unloading operations at the ports. Figure 1 presents an example to illustrate the routing and scheduling of three vessels considering seven ports within a planning horizon of eight days. The second vessel starts its voyage from port 3 in period 1 and sails from port 3 to reach port 4 and performs its operations at port 4 in period 2 . The vessel departs from port 4 in period 2 and reaches port 5 in period 4 to carry out its loading/unloading operations. Later the second vessel visits port 7 in period 5 and finally ends its journey at port 6 in period 7 . The routes pertaining to first and third vessel can be depicted from the figure. Stock level or inventory level of 
the containerized cargo at each port is continuously monitored throughout the planning horizon. MIRP aims to identify the total numbers of containers carried by each ship from one port to another for meeting the demand for certain ports. Presence of multiple number of berths allows several ships to simultaneously perform their loading/unloading operation at a port in a given time period.

\section{$<<$ Insert Figure 1 >>}

The problem employs slow steaming policy as a possible measure in order to capture the sustainability aspects. As mentioned by Norstad et al. 2011, fuel consumed by the vessel depends upon the ship's sailing speed. The relationship between vessel speed and fuel consumption is incorporated to estimate the fuel cost at the sea. And fuel cost at the port is computed based on the total time spent by the vessel at a certain port. It is assumed that the vessel operates on heavy fuel oil (Low-Sulphur Fuel Oil) when in sea and marine diesel oil while at port. Slow steaming policy leads to increase in the travelling time of the vessel from one port to another. Vessel sailing at normal speed reaches the port before the starting of the time window, thereby incurring penalty charges for waiting. Moreover, multiple vessels arriving before the starting of the time window increases the port congestion. Slow steaming helps the ship to avoid congestion as well as early arrival at the port. Figures 2 illustrate two scenarios of the vessel travelling from one port to another with normal speed and while sailing by employing slow steaming. An example of two ports (distance between the ports is 286 nautical miles or $529.67 \mathrm{~km}$ ) is considered to explain the magnitude of the time windows and vessel sailing time with respect to normal speed and slow steaming. Port operations are carried out within the specific time window ranging from 8 am to $5 \mathrm{pm}$ and 9 am to $6 \mathrm{pm}$ for port A and port B respectively. Suppose, the vessel departs from port A at $6 \mathrm{pm}$ and sails at a normal speed of 22 knots taking around 13 hours to reach port $\mathrm{B}$. The vessel arrives at the port B around $7 \mathrm{am}$ before the starting of the time window, thereby incurring a penalty cost for waiting. Although, if the vessel had performed its voyage at 17.875 knots, then it would have arrived at port B by 10am within the time window. Moreover, considering slow steaming while sailing from one port to another helps to reduce the total amount of fuel consumed by the vessel.

$<<$ Insert Figure 2 >>

Multiple vessels performing their operation at a port in a specific time period depends upon the number of berths available. This in turn leads to arrival of several ships at a given period and thereby increases the port congestion. The consideration of time window concept in the problem helps to enhance the service level by reducing the congestion level at the port. As different ports have specific restricted operating time (certain ports are closed during night), hence it is essential to incorporate the time window concept to smoothly carry out the port operation. Port operation time involves set-up time (time required to arrange the quay cranes) and variable time depending upon the number of containers loaded/unloaded. A setup cost is incurred, if any loading/unloading operation takes place at a port. Generally, a port operation should start with the starting of the time window and ends with the ending of the time window. However, there can be two possibilities - the ship may arrive much before the starting of the time window and it may arrive well after the starting of the time window. For the 
first case, a penalty cost is charged for waiting outside the time window. In second case, the vessel may end up finishing its operation after the ending of the time window. In order to counter such violation, a penalty cost is incurred depending upon the number of hours operated outside the time window. Such operating measures associated with time window helps in improving the port management facilities. Figure 3 depicts the pictorial description of the time window concept.

$<<$ Insert Figure 3>>

A Mixed Integer Non-Linear Programming (MINLP) model is developed on the basis of the problem described earlier. The mathematical formulation presented in the next section includes different variables - dependent, independent, interactive and incorporates several constraints conceiving the practical scenarios. Based on the storage capacity of the ships and the ports, different constraints related to the loading/unloading operation are considered. Relationship pertaining to the number of containers loaded/unloaded on the ship and the maximum capacity of the vessel is taken into account. Other constraints consider the connection between the total numbers of containers on-board a certain ship while sailing from one port to another and the number of containers loaded/unloaded. Demand satisfying constraints and storage capacity constraints for each ports are also presented. Owing to the inherent complexity of the problem, an efficient search heuristic named Particle Swarm Optimization for Composite Particle is used for solving purpose.

\section{MATHEMATICAL MODEL}

In this section, the mathematical formulation for the aforementioned problem is presented. The model is a variant of the core maritime inventory routing problem with special addition of fuel consumption equations, inventory related constraints and service time related costs. Following assumptions are considered for the aforementioned problem:

1. The model is developed keeping in mind of the number of berths available at each port.

2. Demand at each port is assumed to be deterministic in nature for every planning horizon.

3. Ship's loading/unloading time is constant for each type of container.

4. Time window range at each port is known beforehand.

5. Every ship sails from one port to another within a feasible speed range.

6. Each vessel has a fixed carrying capacity.

7. Time window can be violated for two scenarios. In first case, the ship arrives before the starting of the time window. In second case, the ship finishes its operation after the ending of the time window. For both the scenarios, penalty cost is incurred for operating/waiting outside the time window.

\section{Indices}

$c \quad$ Type of containers

$p, q \quad$ Ports

$t, u \quad$ Time period

$v \quad$ Vessels 
$p_{v} \quad$ Initial position of vessel $v$

Sets

$C \quad$ Set of type of containers

$P \quad$ Set of ports

$V \quad$ Set of vessels

$T \quad$ Set of time periods

\section{Parameters}

$R_{c p} \quad$ Fixed cost related to the setup of loading/unloading operation of container of type $c$ at port $p$

$R_{p t}^{E} \quad$ Penalty cost (per hour) incurred at port $p$, when the vessel operates after the ending of the time window in period $t$

$R_{p t}^{S} \quad$ Penalty cost incurred per hour if the ship waits at port $p$ before the starting of the time window in period $t$

$R_{p t}^{F} \quad$ Variable cost (per hour) associated with the loading/unloading operation at port $p$ in period $t$

$f_{p v} \quad$ Fuel consumption at port $p$ for vessel $v$ (in tonnes per hour)

$B_{p t}^{S} \quad$ Beginning of time window at port $p$ in period $t$

$B_{p t}^{E} \quad$ End of time window at port $p$ in period $t$

$A_{v p t} \quad$ Expected arrival time at port $p$ for vessel $v$ in period $t$

$a_{v p t}, \overline{a_{v p t}}$ Earliest and latest arrival times at port $p$ for vessel $v$ in period $t$

$\beta_{p c} \quad$ Time to load/unload a single container of type $c$ at port $p$

$\alpha_{p c} \quad$ Set up time required for carrying out a loading/unloading operation for containers of type $c$ at port $p$

$L_{p q} \quad$ Distance between port $p$ and $q$

$M_{v} \quad$ Maximum capacity of vessel $v$

$D_{c p t} \quad$ Demand of container type $c$ at port $p$ in period $t$

$\lambda_{p c} \quad$ Capacity of container type $c$ at port $p$

$J_{p c} \quad=1$, if port $p$ is a supplier of container type $c$

$$
=-1 \text {, if the port } p \text { has a demand of container type } c
$$

$\delta_{p q v}, \overline{\delta_{p q v}}$ Feasible speed range for every vessel $v$ while travelling from port $p$ to port $q$

$\theta_{p} \quad$ Maximum number of berths at port $p$

$\rho \quad$ Average fuel price for Marine Diesel Oil (MDO)

$\sigma \quad$ Average fuel price for Heavy Fuel Oil (HFO) 


\section{Variables}

$F_{p q v} \quad$ Fuel consumption for vessel $v$ (in tonnes per nautical mile) while travelling from port $p$ to port $q$.

$a_{v p t} \quad$ Arrival time at port $p$ for vessel $v$ in period $t$

$b_{v p t} \quad$ Time operated by vessel $v$ after the ending of the time window at port $p$ for period $t$

$\tau_{v p t} \quad$ Starting time of operation of vessel $v$ at port $p$ in period $t$

$\tau_{v p t}^{E} \quad$ Ending time of the operation at port $p$ for vessel $v$ in period $t$

$K_{v p c t}$ Total number of container of type $c$ loaded/unloaded at port $p$ from vessel $v$ in period $t$. Assuming $K_{v p c t}=0$ if $J_{p c}=0$ or $t=1$

$N_{v p c t} \quad$ Total number of container of type $c$ on vessel $v$ while leaving port $p$ in period $t$ Assuming $N_{v p c t}=0$, if $p \neq p_{v}$

$\eta_{c p t} \quad$ Stock level of container type $c$ at port $p$ in period $t$

$\delta_{p q v} \quad$ Velocity of vessel $v$ while travelling from port $p$ to port $q$

$s_{v p t}=1$, if vessel $v$ terminates its route at port $p$ after an operation in period $t$, $=0$, otherwise,

$y_{\text {ptquv }}=1$, if vessel $v$ initiates its operation in period $t$ at port $p$ and then travels from port $p$ to $q$ and begins its operation in period $u$ at port $q$, $=0$, otherwise. Assuming $y_{\text {ptquv }}=0$, if $t \geq u$; or $p=q$

$\mu_{v p c t}=1$, if container type $c$ is loaded or unloaded from vessel $v$ at port $p$ in period $t$, $=0$, otherwise. Assuming $\mu_{v p c t}=0$, if $J_{p c}=0$; or $t=1$

\section{Objective function}

\section{Minimize}

$$
\begin{aligned}
& \rho \sum_{p \in P} \sum_{t \in T} \sum_{v \in V} f_{p v}\left(\tau_{v p t}^{E}-a_{v p t}\right)+\sigma \sum_{p, q \in P} \sum_{t, u \in T} \sum_{v \in V} L_{p q} F_{p q v} y_{p t q u v}+\sum_{p \in P} \sum_{t \in T} \sum_{v \in V} \sum_{c \in C} R_{c p} \mu_{v p c t} \\
& +\sum_{p \in P} \sum_{t \in T} \sum_{v \in V} R_{p t}^{S}\left[\operatorname{Max}\left(0,\left(B_{p t}^{S}-a_{v p t}\right)\right)\right]+\sum_{p \in P} \sum_{t \in T} \sum_{v \in V} R_{p t}^{E} b_{v p t}+\sum_{p \in P} \sum_{t \in T} \sum_{v \in V} \sum_{c \in C} R_{p t}^{F} \beta_{p c} K_{v p c t}
\end{aligned}
$$

\section{Constraints}

$$
\begin{array}{ll}
F_{p q v}=0.0036 \delta_{p q v}^{2}-0.1015 \delta_{p q v}+0.8848, & \forall p, q \in P, \forall v \in V \\
\delta_{p q v} \leq \delta_{p q v} \leq \overline{\delta_{p q v}}, & \forall p, q \in P, \forall v \in V
\end{array}
$$

Equation (1) represents the objective function of the formulation depicting the total cost incurred for a shipping company operating several vessels on different routes in a planning horizon to meet the demand and supply for all the ports. The first and second term of the objective function is related to the fuel cost of the vessel while at port and sea respectively. The third term interprets the total set up cost required for the loading/unloading operation. Fourth term is associated with the penalty cost for waiting before the start of the time window. Fifth term provides the demurrage charges incurred when 
the vessels fails to finish its operation within the allotted time window. Sixth term calculates the total operation cost inside the time window.

It is assumed that engine of the each vessel works on heavy fuel oil (Low-Sulphur Fuel Oil) when it is in sea and marine diesel oil when it is in port. Accordingly, the average fuel prices considered are 463.50 USD/ton for Heavy Fuel Oil (Low-Sulphur Fuel Oil) and 586 USD/ton for Marine Diesel Oil as mentioned in kontovas et al. 2011.

Equation (2) presents the relationship between fuel consumption and vessel speed for a ship with load capacity around $150,000 \mathrm{~m}^{3}$. Norstad et al. 2011 studied that for a feasible speed range between 14.1 knots to 22 knots, the equation holds good for estimating the total fuel consumption of the vessel. Equation (3) provides the upper and lower bounds for vessel speed variables.

$$
\begin{array}{ll}
\sum_{q \in P} \sum_{u \in T} \sum_{v \in V} y_{q u p t v} \leq \theta_{p}, & \forall p \in P, \forall t \in T \\
\sum_{q \in P} \sum_{u \in T} y_{p_{v} 1 q u v}+s_{v 1 p_{v}}=1, & \forall v \in V \\
\sum_{p \in P} \sum_{t \in T} s_{v p t}=1, & \forall v \in V \\
\sum_{q \in P} \sum_{u \in T} y_{q u p t v}-\sum_{q \in P} \sum_{u \in T} y_{p t q u v}-s_{v p t}=0 & \forall p \in P, \forall t \in T, t>1, \forall v \in V \\
\mu_{v p c t} \leq \sum_{q \in P} \sum_{u \in T} y_{q u p t v}, & \forall p \in P, \forall t \in T, t>1, \forall v \in V, \forall c \in C
\end{array}
$$

Equations (4) - (8) represent the ship routing constraints. Constraint (4) depicts for a given time period, maximum number of ship that can operate at a port, depending upon the number of berths available. Constraint (5) ensures that a vessel might travel from its initial port $p_{v}$ to port $q$ or it may end its route at a certain port. Constraint (6) guarantees that a vessel must end its route at some port. Flow conservation constraints are given by equation (7). Constraint (8) relates a scenario where if a vessel is being operated at a port in a given time period, then certainly that port must belong to the vessel's route.

$$
\begin{array}{ll}
\tau_{v p t}-A_{v p t} \geq 0, & \forall p \in P, \forall t \in T, \forall v \in V \\
\tau_{v p t} \geq a_{v p t}, & \forall p \in P, \forall t \in T, \forall v \in V \\
a_{v p t} \leq a_{v p t} \leq \overline{a_{v p t}}, & \forall p \in P, \forall t \in T, \forall v \in V \\
B_{p t}^{s} \leq \tau_{v p t} \leq B_{p t}^{E}, & \forall p \in P, \forall t \in T, \forall v \in V \\
\left(\tau_{v p t}^{E}+\frac{L_{p q}}{\delta_{p q v}}-a_{v q u}\right) y_{p t q u v} \leq 0, & \forall p, q \in P, \forall t, u \in T, \forall v \in V \\
\left(\tau_{v p t}^{E}+\frac{L_{p q}}{\delta_{p q v}}-a_{v q u}\right) y_{p t q u v}=0, & \text { When, } y_{p t q u v}=0 \\
\tau_{v p t}^{E}=\tau_{v p t}+\sum_{c \in C} \alpha_{p c} \mu_{v p c t}+\sum_{c \in C} \beta_{p c} K_{v p c t}, & \forall p \in P, \forall t \in T, \forall v \in V \\
b_{v p t} \geq \tau_{v p t}^{E}-B_{p t}^{E} & \forall p \in P, \forall t \in T, \forall v \in V \\
\tau_{v p t}-\tau_{v p(t-1)}^{E} \geq 0, & \forall p \in P, \forall t \in T, \forall v \in V, p>1
\end{array}
$$


Equations (9) - (16) represent the time window constraints. Constraint (9) ensures that the vessel must start its operation at a port after its expected arrival time. Constraint (10) guarantees that a ship must arrive at the port before the starting of its loading/unloading operation for a given time period. The time interval within which the ship is expected to arrive is given by constraint (11). The range for the time window horizon is mentioned in constraint (12). Constraint (13) states that the arrival time of the operation at port $q$ must be greater than the departure time of the ship from previous port $p$ plus the sailing time between two ports. Constraint (13b) is considered in place of constraint (13), if the ship doesn't travels from port $p$ to $q$ then naturally $y_{\text {ptquv }}$ becomes zero $\left(y_{p t q u v}=0\right)$. Constraint (14) means that the ending time of each operation must be equal to the starting time of the operation plus the total service time. More precisely, service time comprises of set up time required for the operation and loading/unloading time for each type of containers. The penalty cost incurred for operating outside the time window is realized using constraint (15). Constraint (16) tackles a specific scenario, where the vessel should always start its operation at a certain port only after it finishes its operation at the previous period.

$$
\begin{array}{ll}
K_{v p c t} \leq M_{v} \mu_{v p c t}, & \forall p \in P, \forall t \in T, \forall v \in V, \forall c \in C \\
y_{p t q u v}\left(N_{v p c t}+J_{q c} K_{v q c u}-N_{v q c u}\right)=0, & \forall p, q \in P, \forall t, u \in T, \forall v \in V, \forall c \in C \\
\sum_{c \in C} N_{v p c t} \leq M_{v} \sum_{q \in P} \sum_{u \in T} y_{p t q u v}, & \forall p \in P, \forall t \in T, \forall v \in V
\end{array}
$$

Equation (17) - (19) represents ship's inventory related constraints. Constraint (17) states that the total number of container loaded/unloaded on the vessel should be less than (or equal to) the maximum carrying capacity of the ship. This constraint imposes an upper bound on the total number of container loaded/unloaded on the ship. Constraint (18) is related to the total number of containers on-board to the number of container loaded/unloaded. It is considered for a scenario where the vessel sails from one port to another. Here, the total capacity on-board a ship while departing from the first port should be equal to the capacity of the ship while leaving the second port plus/minus the number of container loaded/unloaded from the second port. Upper bound on the total capacity carried by a ship is imposed by the constraint (19). It states that if the total capacity on-board a certain ship is positive, then it must travel from one port to another.

$$
\begin{array}{ll}
\eta_{c p(t-1)}+\sum_{v \in V} K_{v p c t}=D_{c p t}+\eta_{c p t}, & \forall p \in P, \forall t \in T, \forall c \in C \\
\eta_{c p t} \leq \lambda_{p c}, & \forall p \in P, \forall t \in T, \forall c \in C
\end{array}
$$

Constrain (20) satisfies the demand for each type of container at every port in each time period. Storage capacity at each port for each type of container is given by constraint (21).

$$
\begin{array}{ll}
y_{p t q u v} \in\{0,1\}, & \forall p, q \in P, p \neq q, \forall t, u \in T, t<u, \forall v \in V \\
s_{v p t} \in\{0,1\}, & \forall p \in P, \forall t \in T, \forall v \in V \\
\mu_{v p c t} \in\{0,1\}, & \forall p \in P, \forall t \in T, \forall v \in V, \forall c \in C \\
F_{p q v}, \delta_{p q v} \geq 0, & \forall p, q \in P, p \neq q, \forall v \in V \\
\eta_{c p t} \geq 0, & \forall p \in P, \forall t \in T, \forall c \in C
\end{array}
$$




$$
\begin{array}{ll}
K_{v p c t}, N_{v p c t} \geq 0, & \forall p \in P, \forall t \in T, \forall v \in V, \forall c \in C \\
\tau_{v p t}, \tau_{v p t}^{E}, b_{v p t}, a_{v p t} \geq 0, & \forall p \in P, \forall t \in T, \forall v \in V
\end{array}
$$

Equations (22) - (24) are the binary variables and equations (25) - (28) represents the non-negativity constraints.

\section{SOLUTION APPROACH}

The model presented in the above section considers different types of variables - binary, continuous (dependent as well as independent) and incorporates several real time constraints. In view of the above modelling approach, the formulation appears to be complex in nature. However, solving such a complex problem using exact solution methods requires high computational effort and tremendous memory requirements as mentioned by Guan et al 2016. MirHassani et al. 2011, Repoussis et al. 2010 highlighted the fact about the lack of exact heuristic techniques to deal with MINLP model makes it imperative to solve the model with random search heuristics. Exact methods have not yet been well researched upon for resolving unconstrained non-linear optimization problems. As a result, such complex problem requires intelligent search heuristics or random search techniques and an advanced variant of Particle Swarm Optimization algorithm is employed. A new kind of nature-inspired algorithm named Particle Swarm Optimization for Composite Particle (PSO-CP) developed by Liu et al. 2010 is deployed to resolve the mixed integer non-linear programming model presented earlier.

Particle swarm optimization algorithm (PSO) is simpler in computer implementation than other random search methods such as genetic algorithm (GA), ant colony optimization (ACO) etc. as mentioned by Aouay et al. 2013. They highlighted the robustness of PSO algorithm in adapting to different domain with their parameters being nearly fixed. Recently a number of researchers have considered particle swarm optimization algorithm due to its straightforward and uncomplicated concept to resolve combinatorial optimization problems in various fields. PSO is a robust stochastic optimization technique based on the movement and intelligence of swarm in a search space. Each swarm comprises of multiple number of particles interacting among each other to locate a global optimum. During an iteration of PSO, the position of the particle is updated using its best-known position and global best position of the solution space. The velocity and position of the particle is updated during the iteration using the equation (29) and (30).

$$
\begin{aligned}
& \overrightarrow{\alpha_{i}}(t+1)=\omega \overrightarrow{\alpha_{i}}(t)+\beta_{1} \vec{\varphi} \times\left(\overrightarrow{\rho_{l}}(t)-\overrightarrow{p_{i}}(t)\right)+\beta_{2} \vec{\varepsilon} \times\left(\overrightarrow{\rho_{g}}(t)-\overrightarrow{p_{i}}(t)\right) \\
& \overrightarrow{p_{i}}(t+1)=\overrightarrow{p_{i}}(t)+\overrightarrow{\alpha_{i}}(t+1)
\end{aligned}
$$

Here, the velocity of $i^{\text {th }}$ particle is represented by $\overrightarrow{\alpha_{i}}(t), \overrightarrow{\alpha_{i}}(t+1)$ for $t^{\text {th }}$ and $(t+1)^{\text {th }}$ iteration. Position of $i^{\text {th }}$ particle for $t^{\text {th }}$ and $(t+1)^{t h}$ iteration is depicted as $\overrightarrow{p_{i}}(t)$ and $\overrightarrow{p_{i}}(t+1) \cdot \overrightarrow{\rho_{l}}(t)$ and $\overrightarrow{\rho_{g}}(t)$ are the local and global best position of the particle. $\omega$ is the inertia weight. Acceleration coefficients are represented by $\beta_{1}$ and $\beta_{2} \cdot \vec{\varphi}$ and $\vec{\varepsilon}$ are the random vectors. The basic concept of PSO algorithm lies in accelerating each particle of the swarm toward its local best position and the global best position for improving the fitness function. 
Several researchers take up the challenge of employing advanced variants of PSO in different applications as most of them provide superior performance than other on-par stochastic optimization techniques. Zhu et al. 2009 employed a particle swarm optimization algorithm for resolving a complex vehicle routing problem in the domain of grain logistics. Other researchers such as Zhang et al. 2015 and Haddar et al. 2016 proposed different hybrid PSO algorithms for dealing with feature selection and multidimensional knapsack problem respectively and compared the result with other state of the art PSO variants, basic genetic algorithm and proving the superiority of hybrid PSO over other algorithms. Several other hybrid particle swarm optimization techniques have been proposed in the literature and successfully applied to different challenging problems such as hybrid PSO with support vector machine (Xu et al. 2015), hybrid PSO with ant colony optimization (Mandloi et al. 2016) and hybrid algorithm based on PSO and artificial bee colony (Li et al. 2015). Gülcü et al. 2015 developed a meta-heuristic called parallel comprehensive learning particle swarm optimization considering multiple swarms. A novel fuzzy particle swarm optimization algorithm having crossmutated operator is proposed by Ling et al. 2016. However, in most of the cases, PSO and their variants suffer from immature convergence or entrapment to a local solution. An advanced version of PSO named particle swarm optimization for composite particle (PSO-CP) was developed by Liu et al. 2010 which overcame the problem of premature convergence by incorporating the concept of 'composite particle' derived from physics and proved its superiority over other state of the art evolutionary algorithms and PSO variants. They stated about the enhanced performance of PSO-CP algorithm in terms of better convergence rate and carrying out an improved exploration and exploitation processes. Moreover, there are other reasons supporting the selection of PSO-CP algorithm for solving the aforementioned mathematical model. PSO-CP employs effective and interactive mechanisms such as construction of composite particles, velocity-anisotropic reflection (VAR) scheme and scattering operation to search for better near optimal solutions. The VelocityAnisotropic Reflection (VAR) scheme helps to define the interaction between the particles for exploring promising region in the search space. The scattering operator used by PSO-CP diversifies the current solution by considering better exploration capability and increases the possibility of arriving at a new optimum.

\subsection{PARTICLE SWARM OPTIMIZATION for COMPOSITE PARTICLE ALGORITHM}

The algorithm begins with initialization of the swarm and random initialization of velocity and position of each swarm. The local best particle and global best particle are updated according to the equation of basic particle swarm optimization algorithm as presented in (29) and (30). Section 5.1.1, 5.1.2 and 5.1.3 elaborately describes different operators of PSO-CP as mentioned in Liu et al. 2010 such as composite particle, Scattering operation, and VAR operation. All the operators of PSO-CP are performed accordingly before updating the velocity and the position of the swarm.

\subsubsection{COMPOSITE PARTICLES}

At first we generate a swarm comprising of all the particles and each particles consists of each type of variables of the mathematical model such as routing variables $\left(y_{p t q u v}, s_{v p t}\right)$, time window variables $\left(a_{v p t}, b_{v p t}, \tau_{v p t}, \tau_{v p t}^{E}\right)$, loading/unloading variables $\left(K_{v p c t}, \mu_{v p c t}\right)$, vessel speed variable $\left(\delta_{p q v}\right)$, fuel consumption variable $\left(F_{p q v}\right)$, flow variable $\left(N_{v p c t}\right)$ and stock level variables $\left(\eta_{c p t}\right)$. Figure 8 demonstrates the schematic representation of the swarm having 100 particles. At first all the particles 
are sorted in order of their increasing fitness function values. The particle with worst fitness value is selected as the first particle of the composite particle. Remaining two particles of the composite particle is selected from the swarm on the basis of the least Euclidean distance with respect to the first particle of the composite particle. So, each composite particle is a combination of three particles selected accordingly as mentioned earlier. Total number of composite particles formed depends upon the swarm size considered for the algorithm. The largest integer number of [(swarm_size-1)/3] determines the number of composite particles. For example, if the swarm size is equal to 50 , then the number of composite particles formed is 16 (the largest integer number of [(50-1)/3] is 16). For 100 particles considered in the swarm presented in figure 8, 33 (the largest integer number of $[(100-1) / 3]$ ) composite particles are formed. Number of individual particles not belonging to the composite particle are called independent particles which can be calculated using the following equation, swarm_size $-3 *[($ swarm_size-1)/3]. For a swarm size of 50 and 100 , the numbers of independent particles are $2(50-3 *[(50-1) / 3]=50-3 * 16=2)$ and $1(100-3 *[(100-1) / 3]=100-3 * 33=1)$ respectively. Figure 4 provides the pseudo code for the construction of the composite particle. The independent particles remaining after the formation of all the composite particles are passed on to the next iteration.

$<<$ Insert Figure 4>>

\subsubsection{SCATTERING OPERATION}

Scattering operation occurs when the composite particle converges. It mainly triggers when the Euclidean distance between the worst member and the furthermost member within a composite particle is less than a threshold limit $\left(D_{k}<\theta\right)$. On the basis of the information obtained from the worst particle, the scattering operation helps the fittest elementary particle to move towards a propitious direction as presented in figure 3 . The figure depicts a composite particle in which $E$ represents the fittest elementary particle and $M_{1}$ and $M_{2}$ are the non-pioneer particles. As the operation takes place, the fittest member of the composite particle scatters towards the direction of $\overrightarrow{M_{1} E}$ and $\overrightarrow{M_{2} E}$ forming two new members $R_{1}$ and $R_{2}$. The new scattering points $R_{1}$ and $R_{2}$ are determined using the repulsion mechanism formula, $\overrightarrow{E R_{1}}=\vec{\phi} \times \overrightarrow{M_{1} E}$ and $\overrightarrow{E R_{2}}=\vec{\phi} \times \overrightarrow{M_{2} E}$. Here, $\vec{\phi}$ represents a random vector generated within a range of maximum and minimum values of stretching step size $\left[R_{\text {step_min }}, R_{\text {step_max }}\right]$. Now the composite particle comprises of three new members $E, R_{I}$ and $R_{2}$ as shown in figure 5.

$<<$ Insert Figure 5>>

The position of the two elementary particles of a composite particle is updated using the following equations:

$x_{i}^{1}=(1+\phi) x_{i}^{\text {pioneer }}-\phi\left(x_{i}^{1}\right)$ 
$x_{i}^{2}=(1+\phi) x_{i}^{\text {pioneer }}-\phi\left(x_{i}^{2}\right)$

Here $x_{i}^{1}, x_{i}^{2}$ are the updated positions of each elementary particles of a $i^{\text {th }}$ composite particle. And $x_{i}^{\text {pioneer }}$ is the current position of the particle with the best fitness value.

Scattering operation is employed to address certain scenarios where the local diversity of the composite particle declines below a particular level. Here, if a composite particle converges, then the particles may form a cluster and it restricts itself from exploring the promising areas. Scatter operation helps the algorithm to overcome such challenging situation and leads to better exploration capability.

\subsubsection{VAR (Velocity-Anisotropic Reflection) OPERATION}

VAR operation is developed to help the elementary particles in cooperating with each other for exploring better solution space. The VAR scheme replaces the elementary particle having the worst fitness value with a new reflection point aiming to exploit a promising region. The pioneer particle amalgamates the whole information obtained from a composite particle. The knowledge gathered is shared with the independent and other composite particles. The pioneer particle also distributes the essential information among the other two elementary particles. Figure 6 depicts the construction of composite particle using VAR operation.

Position of the worst particle and the other two elementary particles of a new composite particles are denoted by $V, A$ and $B . N$ denotes a randomly generated point on the straight line joined between $A$ and $B$. Now, a reflection point $R$ is generated using the formula, $\overrightarrow{V R}=\overrightarrow{V N}+R_{\text {step }} \vec{\gamma} \times \overrightarrow{V N} . R_{\text {step }}$ is the reflection size parameter and $\gamma$ denotes a random vector. If the reflection point $R$ is better than $V$ in terms of the fitness then the composite particle is reflected towards the point $R$.

$<<$ Insert Figure 6>>

The VAR operation is carried out using the following equation

$x_{i}^{R}=x_{i}^{n}+R_{\text {step }} \gamma \times\left(x_{i}^{\text {worst }}-x_{i}^{n}\right)$,

Where $x_{i}^{R}$ represents the position of the reflection point R. $x_{i}^{n}$ is the position of the point $N$. The position of the worst particle in $i^{\text {th }}$ composite particle is $x_{i}^{\text {worst }}$. Figure 7 presents the flowchart explaining the relationship between composite particle, scattering operation and VAR operation.

$<<$ Insert Figure 7>>

\subsection{INITIAL SOLUTION}

Each algorithm requires an initial feasible solution and the appropriate repair mechanism to provide a near optimal solution at the end. In this regard, we wish to mention that a similar procedure is 
employed to perform the repair mechanism within the algorithm which checks the feasibility of the solution obtained after the iteration and discards the infeasible solution.

The formulation has different types of variables such as routing variables $\left(y_{p t q u}, s_{v p t}\right)$, time window variables $\left(a_{v p t}, b_{v p t}, \tau_{v p t}, \tau_{v p t}^{E}\right)$, loading/unloading variables $\left(K_{v p c t}, \mu_{v p c t}\right)$, vessel speed variable $\left(\delta_{p q v}\right)$, fuel consumption variable $\left(F_{p q v}\right)$, flow variable $\left(N_{v p c t}\right)$ and stock level variables $\left(\eta_{c p t}\right)$. Before starting the searching procedure, every algorithm requires an initial feasible solution comprising of all the decision variables of the mathematical model. For a certain problem instance, initially the routes are generated for all the ships considering their initial port position. Values of the route variables $\left(y_{p t q u v}\right.$ and $\left.s_{v p t}\right)$ are obtained from the generated ship routes and their feasibility checking is performed by satisfying equations (4), (6) and (7). The value of the loading variable $\left(\mu_{v p c t}\right)$ is estimated using the route variable $\left(y_{\text {ptquv }}\right)$ and equation (8). If the loading/unloading operation is performed in a port, then surely the value of the time window variables $\left(a_{v p t}, \tau_{v p t}\right)$ should be greater than zero. Hence, the values of $a_{v p t}$ and $\tau_{v p t}$ are computed using the range presented in equation (11) and (12) respectively. Feasibility checking of the values obtained is checked by satisfying equations (9) and (10) and infeasible values discarded. Considering the binary variable $\mu_{v p c t}$, the value of the loading variable $K_{v p c t}$ is computed within a particular range. Feasibility of the values of $K_{v p c t}$ is checked using equation (17). Decision variables pertaining to the ending time of the operation $\tau_{v p t}^{E}$ is obtained using the values of $\tau_{v p t}, \mu_{v p c t}, K_{v p c t}$ and equation (14). The penalty variables $b_{v p t}$ associated with the violation of time window is computed using equation (15). The vessel speed variables $\delta_{p q v}$ are generated within the specific feasible range of 14-22knots. Feasibility of the vessel speed variable is checked using the values of the $\tau_{v p t}^{E}, a_{v p t}, y_{p t q u}$ and equation (13) and (13b). Fuel consumption of the vessel $F_{p q v}$ is computed using the value of the vessel speed variable and equation (2). Stock level variable $\eta_{c p t}$ is obtained within a particular range by satisfying the equation (21). The value of the flow variable $N_{v p c t}$ is obtained within a given range and equation (19). Now considering the value of the binary variable $y_{\text {ptquv }}$ and equation (18), the flow variable $N_{v p c t}$ is updated. Initialization of the solution is presented in a way as mentioned in the literature for different nature of problems such as routing, scheduling etc. The initial solution generated is fed into each of the algorithm to start their respective procedures.

\subsection{SWARM REPRESENTATION}

Every swarm is comprised of each type of variables such as routing variables, time window variables, vessel speed variables and container related variables. Table 1 illustrates different types of variables presented in a swarm for an example of 3 ports, 2 types of containers, 3 time periods and 2 vessels. Figure 8 depicts the schematic representation of the swarm structure for the given example. Figure 9 presents the flowchart of the particle swarm optimization for composite particle (PSO-CP) algorithm. 
$<<$ Insert Table 1 >

$<<$ Insert Figure 9>>

\subsection{PARTICLE SWARM OPTIMIZATION - DIFFERENTIAL EVOLUTION (PSO-DE)}

Epitropakis et al. 2012 presented a hybrid approach combining particle swarm optimization (PSO) with differential evolution (DE) algorithm. The algorithm aims to guide towards the global best value without compromising the searching capabilities of the swarm in the solution space. PSO-DE exploits the best position information using an efficient procedure known as differential evolution. Based on the position of the swarm, the evolutionary algorithm will either exploit the already found regions in the search space or explore new areas in the solution space. The population present in the swarm considers the set of best personal experience is used for the algorithm procedure. PSO-DE has a fast converging rate as it keeps on exploring the promising regions in the search space or exploits the already discovered areas. Figure 8 depicts the pseudo code of PSO-DE algorithm. At first, the swarm undergoes certain changes after the classical particle swarm optimization procedures, and later it evolves through a differential evolution algorithm. The classical PSO mainly explores search space and focuses on the new encouraging areas in the search space. The DE has a two-fold purpose. In the initial generations, it explores the potential areas in the solution space and later it concentrates on the promising explored regions.

The swarm contains the personal best position of each particle at the $\mathrm{n}^{\text {th }}$ iteration. The swarm structure considered for the mathematical model is similar to that of the neighborhood structure presented in the earlier section. In a single iteration, the swarm undergoes the updating of the velocity and position according to the classical PSO algorithm equations. The fitness of each particle in the current position is compared with that of the local best position and accordingly updated. The particle with the best fitness in the local best position is considered as the global best position. Each particle undergoes certain changes after the differential evolution algorithm (mutation, recombination, and selection) steps. In the mutation step, a mutant vector $h_{n}(i)$ is generated for each particle using the following equation (32).

$h_{n}(i)=P_{-} \operatorname{Best}_{n}\left(r_{1}\right)+F\left(P_{-} \operatorname{Best}_{n}\left(r_{2}\right)-P_{-} \operatorname{Best}_{n}\left(r_{3}\right)\right)$

Here, $r_{1}, r_{2}$ and $r_{3}$ are the randomly generated numbers between 1 to the total number of particles in the swarm. F (binomial crossover) is considered 0.5 as mentioned in Epitropakis et al. 2012. P_Best $t_{n}$ is the local best position.

Now the selection procedure is applied between the previous best position and the new best position and the fittest one selected. A detailed algorithm scheme of PSO-DE approach is illustrated in Figure 10. The value of CR used in the algorithm is considered 0.9 as presented in Epitropakis et al. 2012.

$<<$ Insert Figure 10>>

\section{COMPUTATIONAL RESULT}

The mathematical formulation developed has been tested on different problems to showcase the efficiency of the proposed model. Each problem considers different instances based on the demand 
and supply of each type of containers at each port. The test instances for each of the problems are mentioned in Table 2. The major computational complexity in resolving such shipping problems are observed due to large number of variables and constraints as shown in Table 2. Seven problems sizes with three instances each are considered to validate the proposed mathematical model as presented in Table 2. Hence, 21 problem instances are solved and some of the problem instances deals with many ports and time periods inspired from the real-world problem associated with the shipping services of Maersk Line.

\section{$<<$ Insert Table 2>>}

\subsection{DATA COLLECTION}

Different types of containers are considered over here depending upon their respective sizes. Generally, shipping companies uses bulk containers for bulk minerals, tank containers for liquid or gases. For transporting organic products requiring ventilation, ventilated containers are used. Temperature controlled - refrigerated, insulated and heated containers are employed while dealing with perishable goods. Container ships predominantly carry 20 -foot and 40 -foot containers and 2 types of containers are considered for each problem sizes. Ship's speed range is between 14.1 knots to 22 knots. Data associated with time window information, different types of costs and storage capacities of ports and ships are appropriately generated as presented in different sources (Barnhart et al. 2007, Cullinane et al. 1999, Chaug et al. 2005, Kontovas et al. 2011 and Agra et al. 2013b). Number of berths at each port is assumed according considering the scenario of multiple ships operating at a port in a given time period. The complete data set for all the parameters are presented in Table 3. Initial ship positions for each problem sizes are mentioned in Table 4. Some of the parameter values of the mathematical model such as number of berths available at the port, time window range of a port, capacity of the port, penalty charges and other fixed and variable costs of the port etc. are known to the port managers. This information needs to be transferred to the shipping company as they perform the optimization for finding the suitable route and schedule for their ships. Certain information related to the possible ship routes, vessel speed, arrival time of different ships at the port, loading/unloading quantity at a port from the vessel etc. are passed on to the terminal managers from the shipping companies. Hence, it can be concluded that a high level of information sharing takes place between port manager and shipping companies.

$$
\begin{aligned}
& <<\text { Insert Table 3>> } \\
& <<\text { Insert Table 4>> }
\end{aligned}
$$

\subsection{PARAMETER SETTINGS}

The aforementioned experiments scenarios are performed on MATLAB R2014a installed in an Intel Core i5 machine having $2.10 \mathrm{GHz}$ processor speed and 8GB RAM. Each problem instances are solved using nature-inspired algorithms such as particle swarm optimization for composite particle algorithm (PSO-CP), particle swarm optimization algorithm (PSO), particle swarm optimizationdifferential evolution (PSO-DE) and genetic algorithm (GA). The parameters of the PSO-CP algorithm are appropriately tuned to obtain near optimal solutions for each of the experiments designed. Important parameters pertaining to PSO-CP algorithm are Euclidean distance limit, acceleration coefficients, inertia weights, diversification parameters and stretching parameters. Diversification parameters and stretching parameters are taken from the sensitivity analysis performed 
by Liu et al. 2010. Repeated test trails have been carried out to predict the most suitable values corresponding to other parameters. Table 5 presents the values for each parameter associated with PSO-CP algorithm.

\section{$<<$ Insert Table 5>>}

\subsection{EFFICACY OF THE ALGORITHMS}

Table 6 depicting the best and worst solutions as well as the mean and standard-deviation obtained after carrying out 30 runs on each algorithm for solving the instance 1 of each problem sizes (values pertaining to instance 2 and 3 are not presented to avoid the redundancy). Mean and the standard deviation of PSO-CP are much better than other algorithms for instance 1 of all the problem sizes which automatically proves the hypothesis of the PSO-CP algorithm. PSO-CP outperforms all the other algorithms as it has the better exploration capability in terms of effectively carrying out the searching procedure to attain promising near optimal solutions. PSO-CP uses different mechanisms such as construction of composite particles which prioritizes the particle with worst fitness value and replaces them with a particle with better fitness by employing VAR operation. Scattering operation of PSO-CP overcomes certain difficult situations where the local diversity of the particles decreases. VAR and scattering operations help PSO-CP to overcome many entrapments and perform improved exploration by exploiting promising solution spaces where as other benchmark algorithms like PSO and GA suffer from premature convergence or getting confined to a local solution. PSO-DE still provides better solution than PSO and GA as it employs differential evolution strategy in basic PSO to explore potential areas in the search space and later focussing on the promising regions. Although, PSO-CP easily outperforms PSO-DE at it employs advanced searching capabilities making it more powerful for overcoming many challenging scenarios and attaining better near-optimal solutions. Computational time required by all the algorithms for solving each of the problem instances are mentioned in Table 7. Computational efficiency of PSO-CP is nearly at par with other benchmark algorithms such as PSO and GA. The presence of different operators in PSO-CP such as composite particle, scattering operation and VAR operation slightly increases the computational time of the algorithm.

$$
\begin{aligned}
& <<\text { Insert Table 6>> } \\
& <<\text { Insert Table 7>> }
\end{aligned}
$$

\subsection{RESULT ANALYSIS}

Every instance for each problem sizes presented in Table 2 is solved using four algorithms - PSO-CP, PSO-DE, PSO and GA. Results pertaining to the total cost associated with each of the problem instances and penalty cost for violating the time window are presented in Table 8 . The results interprets a substantial difference in the values obtained using all the algorithms. The visual illustrations of the convergence of the solutions for the second instance of problem size $(6,5,2,3)$ and the first instance of problem size $(8,7,2,4)$ are presented in Figure 11 and 12 respectively. The graph shows the convergence of all the four algorithms for two different problem instances. From the figures, it is amply clear that PSO and GA get trapped in local optima as it converges early for all the problem instances. PSO-CP requires more iteration to converge to a near-optimal solution as it extensively explores the search space with help of scattering mechanism and VAR operation. Fuel cost for all the problem instances while sailing at sea and operating at port is presented in Table 9 
helps to understand the sustainability aspects of the mathematical model. Results obtained for different algorithms are compared with each other and presented in the Table 9. Observation from the Table 8 and 9 highlights that majority of the cost incurred for the shipping company largely comprises of the fuel cost. Hence, the possible measures like slow steaming policy should be considered by the shipping companies for minimizing the fuel cost which in turn will reduce their total cost. This fuel cost might be higher for shipping companies which are still unfavourable to the environmental aspects by not considering sustainable strategies. The result obtained out of this work will help the authorities to rethink about their current shipping plans and look to incorporate new measures for maintaining sustainable maritime operations and reduce the overall transportation cost. Table 10 presents the ships routes, different vessel speed and fuel consumption (tonnes per nautical mile) associated with each route and total inventory carried by every vessel on a certain route. The values mentioned in Table 10 are obtained after performing the computational experiment on instance 1 (values related to instance 2 and 3 are not presented to avoid the redundancy) for all the problem sizes. This additional information clarifies the relevance of the study by giving an idea about the output of the mathematical model.

\author{
$<<$ Insert Table 8>> \\ $<<$ Insert Table 9>> \\ $<<$ Insert Table 10〉> \\ $<<$ Insert Figure 11>> \\ $<<$ Insert Figure 12〉> \\ $<<$ Insert Figure 13>>
}

\title{
7. CONCLUSION
}

In this paper, a mathematical model is developed to address a maritime inventory routing problem. The model integrates non-linear relationship between vessel speed and fuel consumption for capturing the sustainability aspects in the formulation. The model is a mixed integer non-linear programming (MINLP) problem considering time window concept and incorporating the routing and scheduling constraints. The formulation also incorporates constraints associated with the ship's inventory. The formulation is solved using PSO-CP and PSO-DE, PSO and GA algorithms separately. Computational results obtained from PSO-CP algorithm for different problem instances are completely dominating the solution of other algorithms. There is a further possibility for extending this mathematical model by incorporating stochastic demand scenarios. Moreover, it is essential to include vessel draft in the formulation to address a new dimension of the port logistics. Also, the model can be made a multi objective one by considering service time as another objective. It can further motivate in employing multi-objective algorithms for solving such formulation. Distributed methods/approaches can be employed in the future researches to solve large size computational problems for improving the computational efficiency. Distributed method generally divides the problem into many tasks and each of it is solved by different computers. Distributed methods are more reliable as it can easily overcome the single point failure faced while performing the same computation on a non-distributed system. The insights evolved out of this paper would help the shipping companies in minimizing the overall cost and readjust the schedule of each ship in an efficient way. 


\section{REFERENCE}

Agra A, Andersson H, Christiansen M, Wolsey L. A maritime inventory routing problem: Discrete time formulations and valid inequalities. Networks. 2013a; 62(4): 297-314.

Agra A, Christiansen M, Delgado A. Mixed integer formulations for a short sea fuel oil distribution problem. Transportation Science. 2013b; 47(1): 108-124.

Agra A, Christiansen M, Delgado A, Simonetti L. Hybrid heuristics for a short sea inventory routing problem. European Journal of Operational Research. 2014; 236(3): 924-935.

Agra A, Christiansen M, Delgado A, Hvattum M L. A maritime inventory routing problem with stochastic sailing and port times. Computers \& Operations Research. 2015; 61: 18-30.

Al-Khayyal F, Hwang S J. Inventory constrained maritime routing and scheduling for multicommodity liquid bulk, Part I: Applications and model. European Journal of Operation Research. 2007; 176(1): 106-130.

Andersson H, Christiansen M, Fagerholt, K. Transportation planning and inventory management in the LNG supply chain. In Energy. Natural resources and environmental economics, Springer. 2010; 427-439.

Andersson H. A maritime pulp distribution problem. INFOR. 2011; 49(2): 125-138.

Andersson H, Fagerholt K, Hobbesland K. Integrated maritime fleet deployment and speed optimization: Case study from RoRo shipping. Computers \& Operations Research. 2015; 55; 233 240.

Aouay, S., S. Jamoussi, and Y.B. Ayed. Particle Swarm Optimization Based Method for Bayesian Network Structure Learning. 2013 5th International Conference on Modeling, Simulation and Applied Optimization, ICMSAO 2013, 0-5. doi:10.1109/ICMSAO.2013.6552569.

Arman D J, Lalla-Ruiz E, Expósito-Izquierdo C, Landa-Silva D, Melián-Batista B. A hybrid GRASPVNS for ship routing and scheduling problem with discretized time windows. Engineering Applications of Artificial Intelligence. 2015; 45: 350 - 360.

Barnhart, C., \& Laporte, G. (2007). Handbooks in operations research \& management science. Transportation, 14, 1-784. http://dx.doi.org/10.1016/S0927-0507(06)14004-9.

Bilgen B, Ozkarahan I. A mixed-integer linear programming model for bulk grain blending and shipping. International Journal of Production Economics. 2007; 107(1): 555-571.

Buhaug Ø, Corbett J. J, Endresen Ø, Eyring V, Faber J, Hanayama S, Lee D. S, Lee D, Lindstad H, Markowska A. Z, Mjelde A, Nelissen D, Nilsen J, Palsson C, Winebrake J. J, Wu W. Q, and Yoshida K. Second IMO GHG Study (London, UK: International Maritime Organisation (IMO)) 2009.

Chaug, I. H., \& Yu, P. H. Shipping economic analysis for ultra large containership. Journal of the Eastern Asia Society for Transportation Studies, 2005; 6, 936-951. 
Christiansen M, Nygreen B. A method for solving ship routing problems with inventory constraints. Annals of Operation Research. 1998; 81(1): 357-378.

Christiansen M. Decomposition of a combined inventory and time constrained ship routing problem. Transportation Science. 1999; 33(1): 3-16.

Christiansen M., Fagerholt K., Nygreen B., Ronen, D. Maritime transportation. In: Barnhart, C., Laporte, G. (Eds.), Transportation. In: Handbooks in Operations Research and Management Science, 2007, vol. 14. North-Holland, Amsterdam, pp. 189-284.

Christiansen M, Fagerholt K, Flatberg T, Haugen O, Kloster O, Lund E H. Maritime inventory routing with multiple products: A case study from the cement industry. European Journal of Operational Research. 2011; 208(1): 86-94.

Cullinane, K., \& Khanna, M. (1999). Economies of scale in large container ships. Journal of Transport Economics and Policy, 33(2), 185-208.

Dauzère-Pérès S, Nordli A, Olstad A, Haugen K, Koester U, Myrstad O P, Teistklub G, Reistad A. Omya hustadmarmor optimizes its supply chain for delivering calcium carbonate slurry to European paper manufacturers. Interfaces. 2007; 37(1): 39-51.

De, A., Mamanduru, V. K. R., Gunasekaran, A., Subramanian, N., \& Tiwari, M. K.. Composite particle algorithm for sustainable integrated dynamic ship routing and scheduling optimization. Computers \& Industrial Engineering, 2016; 96, 201-215.

Engineer F G, Furman K C, Nemhauser G L, Savelsbergh M W P, Song J H. A Branch-Price-AndCut algorithm for single product maritime inventory routing. Operations Research. 2012; 60(1): 106122.

Epitropakis, M. G., Plagianakos, V. P., \& Vrahatis, M. N. Evolving cognitive and social experience in Particle Swarm Optimization through Differential Evolution: A hybrid approach. Information Sciences, 2012; 216, 50-92.

Fagerholt K, Gausel T N, Rakke G J, Psaraftis N H. Maritime routing and speed optimization with emission control areas. Transportation Research Part C. 2015; 52: 57-73.

Fodstad M, Uggen K T, Rømo F, Lium A, Stremersch G. LNGScheduler: A rich model for coordinating vessel routing, inventories and trade in the liquefied natural gas supply chain. Journal of Energy Markets. 2010; 3(4): 31-64.

Furman K C, Song J, Kocis G R, McDonald M K, Warrick P H. Feedstock routing in the ExxonMobil downstream sector. Interfaces. 2011; 41(2): 149-163.

Goel V, Furman K C, Song J H, El-Bakry A S. Large neighbourhood search for LNG inventory routing. Journal of Heuristics. 2012; 18(6): 821-848.

Grønhaug R, Christiansen M, Desaulniers G, Desrosiers J. A Branch-and-Price method for a liquefied natural gas inventory routing problem. Transportation Science. 2010; 44(3): 400-415. 
Guan J, Lin G. Hybridizing variable neighborhood search with ant colony optimization for solving the single row facility layout problem. European Journal of Operational Research. 2016; 248(3): 899909.

Gülcü Ş, Kodaz H. A novel parallel multi-swarm algorithm based on comprehensive learning particle swarm optimization. Engineering Applications of Artificial Intelligence. 2015; 45(1): 33-45.

Haddar B, Khemakhem M, Hanafi S, Wilbaut C. A hybrid quantum particle swarm optimization for the Multidimensional Knapsack Problem. Engineering Applications of Artificial Intelligence. 2016; 55()$: 1-13$.

Hemmati A, Hvattum M L, Christiansen M, Laporte G. An iterative two-phase hybrid matheuristic for a multi-product short sea inventory-routing problem. European Journal of Operational Research. 2016; 252(3): 775-788.

Hennig F, Nygreen B, Christiansen M, Fagerholt K, Furman C K, Song J, Kocis R G, Warrick H P. Maritime crude oil transportation - A split pickup and split delivery problem. European Journal of Operational Research. 2012; 218 (3): 764-774

Hewitt M, Nemhauser G L, Savelsbergh M W P, Song J H. A Branch and Price guided search approach to maritime inventory routing. Computers \& Operations Research. 2013; 40(5): 1410-1419.

ICS, World Trade and the Reduction of $\mathrm{CO}_{2}$ Emissions. London: International Chamber of Shipping 2009.

Kontovas C, Psaraftis N H. Reduction of emissions along the maritime intermodal container chain: operational models and policies. Maritime Policy \& Management. 2011; 38(4): 451 - 469.

Li J, Karimi I, Srinivasan R. Efficient bulk maritime logistics for the supply and delivery of multiple chemicals. Computers \& Chemical Engineering. 2010; 34(12): 2118-2128.

Li Z, Wang W, Yan Y, Li Z. PS-ABC: A hybrid algorithm based on particle swarm and artificial bee colony for high-dimensional optimization problems. Expert Systems With Applications, 2015; 42(22): 8881-8895.

Ling H S, Chan Y K, Leung H F F, Jiang F, Nguyen H. Quality and robustness improvement for real world industrial systems using a fuzzy particle swarm optimization. Engineering Applications of Artificial Intelligence. 2016; 47, 68-80.

Liu L, Yang S, Wang D. Particle Swarm Optimization with Composite Particles in Dynamic Environments. IEEE Transactions on Systems, Man, and Cybernetics-Part b: Cybernetics. 2010; 40(6): 1634-1648.

Mandloi M, Bhatia V. A low-complexity hybrid algorithm based on particle swarm and ant colony optimization for large-MIMO detection. Expert Systems With Applications, 2016; 50(1): 66-74.

Meng Q, Wang S. Optimal operating strategy for a long-haul liner service route. European Journal of Operational Research. 2011; 215(1): 105 - 114. 
MirHassani, S. A., \& Abolghasemi, N. A particle swarm optimization algorithm for open vehicle routing problem. Expert Systems With Applications, 2011, 38(9): 11547-11551.

Norstad I, Fagerholt K, Laporte G. Tramp ship routing and scheduling with speed optimization. Transportation Research Part C, 2011, 19(5), 853-865.

Papageorgiou J D, Cheon M-S, Nemhauser G, Sokol J. Approximate dynamic programming for a class of long- horizon maritime inventory routing problems. Transportation Science. 2014a; 49(4): 870-885.

Papageorgiou J D, Keha B A, Nemhauser L G, Sokol J. Two-Stage Decomposition Algorithms for Single Product Maritime Inventory Routing. Informs Journal on Computing. 2014b; 26(4): 825-847.

Psaraftis N H, Kontovas A C. Balancing the economic and environmental performance of maritime transportation. Transportation Research Part D. 2010; 15(8): 458 - 462.

Psaraftis N h, Kontovas A C. Speed models for energy-efficient maritime transportation: A taxonomy and survey. Transportation Research Part C. 2013; 26: 331-351.

Repoussis, P. P., Tarantilis, C. D., Braysy, O., \& Ioannou, G. A hybrid evolution strategy for the open vehicle routing problem. Computers \& Operations Research, 2010: 37(3), 443-445.

Rocha R, Grossmann I E, de Aragão M V P. Cascading knapsack inequalities: reformulation of a crude oil distribution problem. Annals of Operations Research. 2013; 203(1): 217-234.

Ronen D. Marine inventory routing: shipments planning. Journal of the Operational Research Society. 2002; 53(1): 108-114.

Ronen D. The effect of oil price on containership speed and fleet size. Journal of the Operational Research Society. 2011; 62: $211-216$.

Shen Q, Chu F, Chen H. A Lagrangian relaxation approach for a multimode inventory routing problem with transshipment in crude oil transportation. Computers \& Chemical Engineering. 2011; 35(10): 2113-2123.

Siswanto N, Essam D, Sarker R. Solving the ship inventory routing and scheduling problem with undedicated compartments. Computers \& Industrial Engineering. 2011; 61(2): 289-299.

Song, J.-H., \& Furman, K. C. A maritime inventory routing problem: Practical approach. Computers \& Operations Research. 2013; 40(3): 657-665.

Uggen K, Fodstad M, Nørstebø V. Using and extending fix-and-relax to solve maritime inventory routing problems. TOP. 2013; 21(2): 355-377.

UNCTAD, Review of Maritime Transport 2013, United Nations Publications, New York and Geneva.

UNCTAD, Review of Maritime Transport 2014, United Nations Publications, New York and Geneva.

UNCTAD, Review of Maritime Transport 2015, United Nations Publications, New York and Geneva. 
Wang S, Meng Q. Sailing speed optimization for container ships in a liner shipping network. Transportation Research Part E. 2012a; 48(3): 701 - 714.

Wang S, Meng Q. Liner ship route schedule design with sea contingency time and port time uncertainty. Transportation Research Part B. 2012b; 46(5): 615 - 633.

Wang S, Meng Q. Robust schedule design for liner shipping services. Transportation Research Part E. 2012c; 48(6): 1093 - 1106.

Xu L, Wang J, Li P Y, Li Q, Zhang X. Resource allocation algorithm based on hybrid particle swarm optimization for multiuser cognitive OFDM network. Expert Systems With Applications. 2015; 42(20): 7186-7194.

Yao Z, Ng H S, Lee H L. A study on bunker fuel management for the shipping liner services. Computers \& Operations Research. 2012; 39(5): 1160 - 1172.

Zhang Y, Zhang L, Neoh C S, Mistry K, Hossain A M. Intelligent affect regression for bodily expressions using hybrid particle swarm optimization and adaptive ensembles. Expert Systems With Applications. 2015; 42(22): 8678-8697.

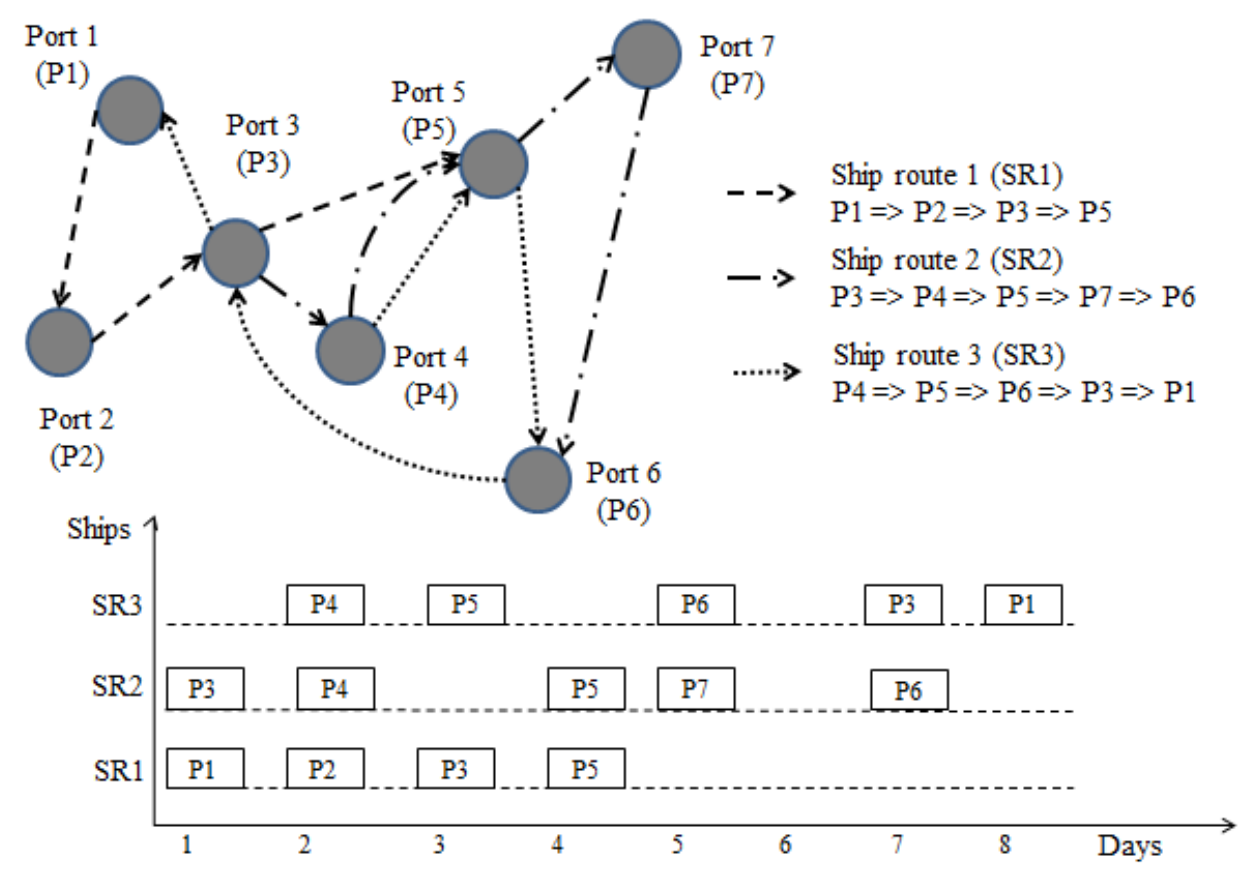

Figure 1. Ship routes within the overall planning horizon 
Travelling time of the vessel with normal speed

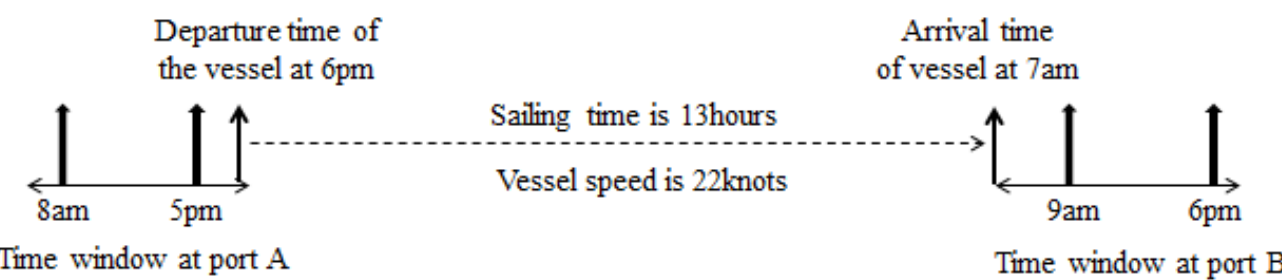

Travelling time of the vessel considering slow steaming

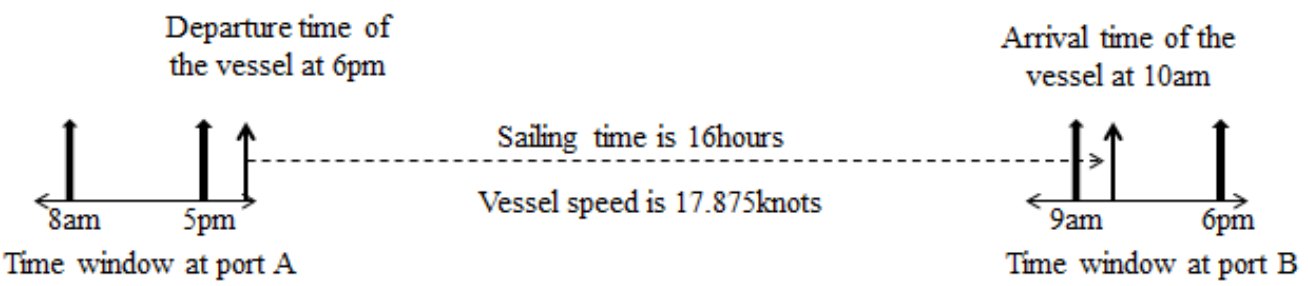

Figure 2. Different travelling time of the vessel considering normal speed and slow steaming

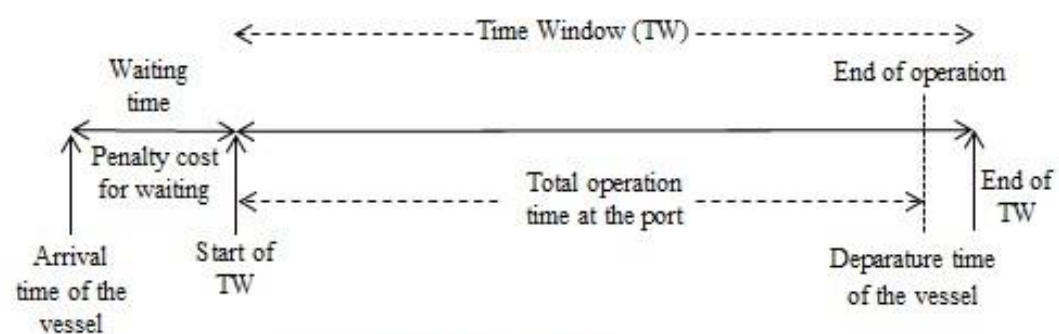

Arrival before time window

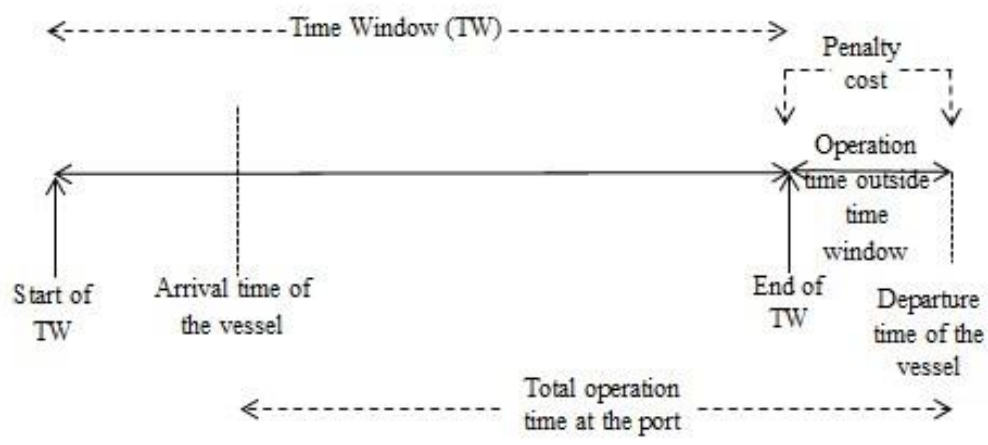

Arrival within time window

Figure 3. Time window at port considering the arrival of vessel for different scenarios 


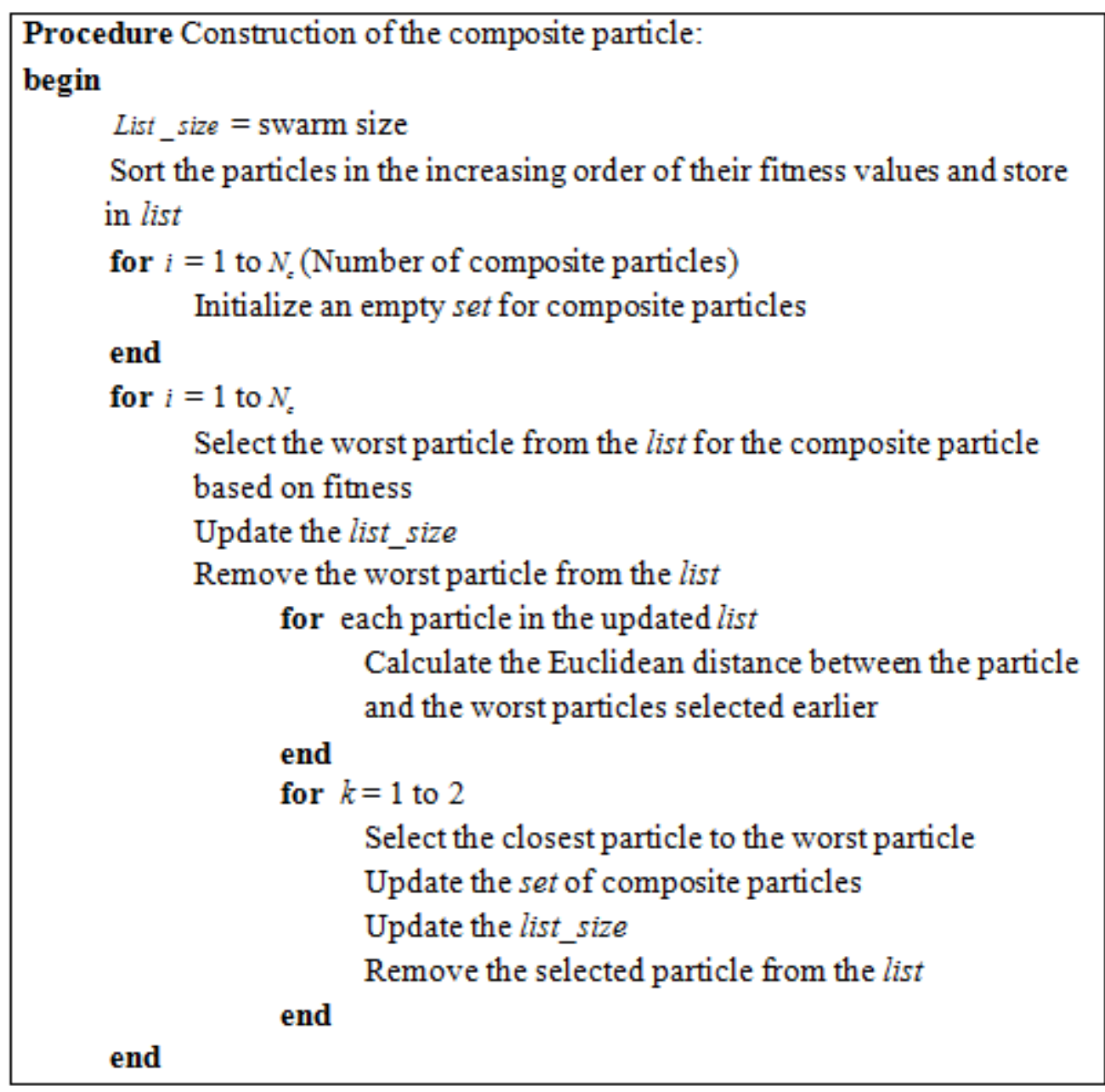

Figure 4. Pseudo code for construction of composite particle as presented by Liu et al. 2010 


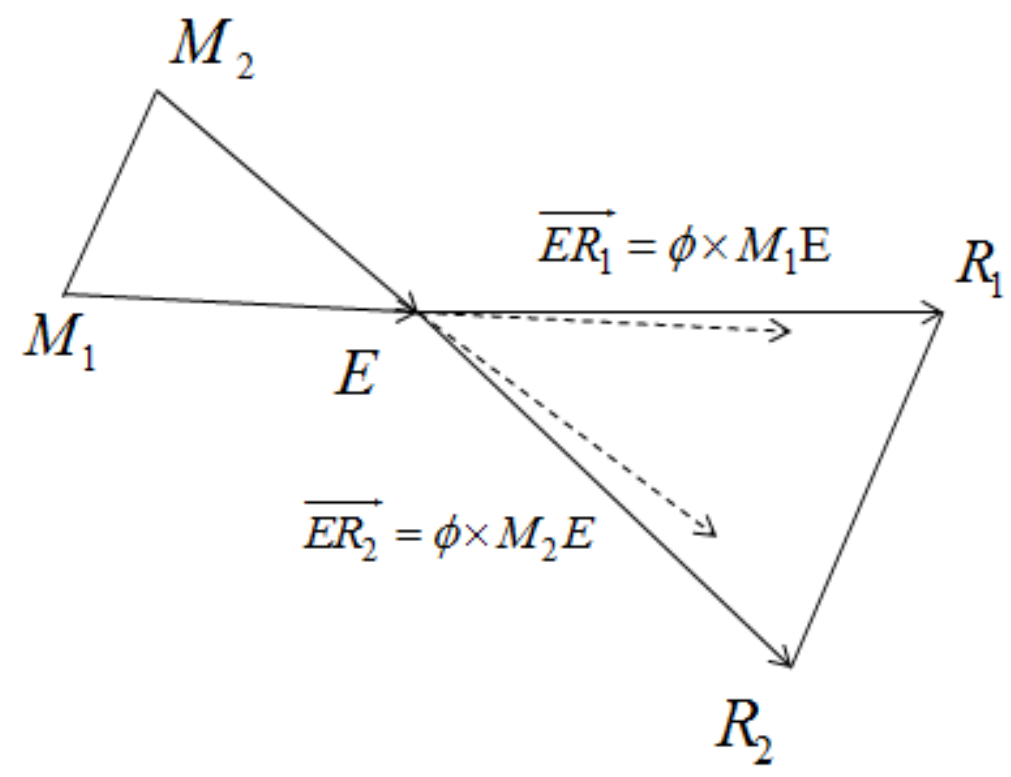

Figure 5. The new composite particle is formed through scattering operation

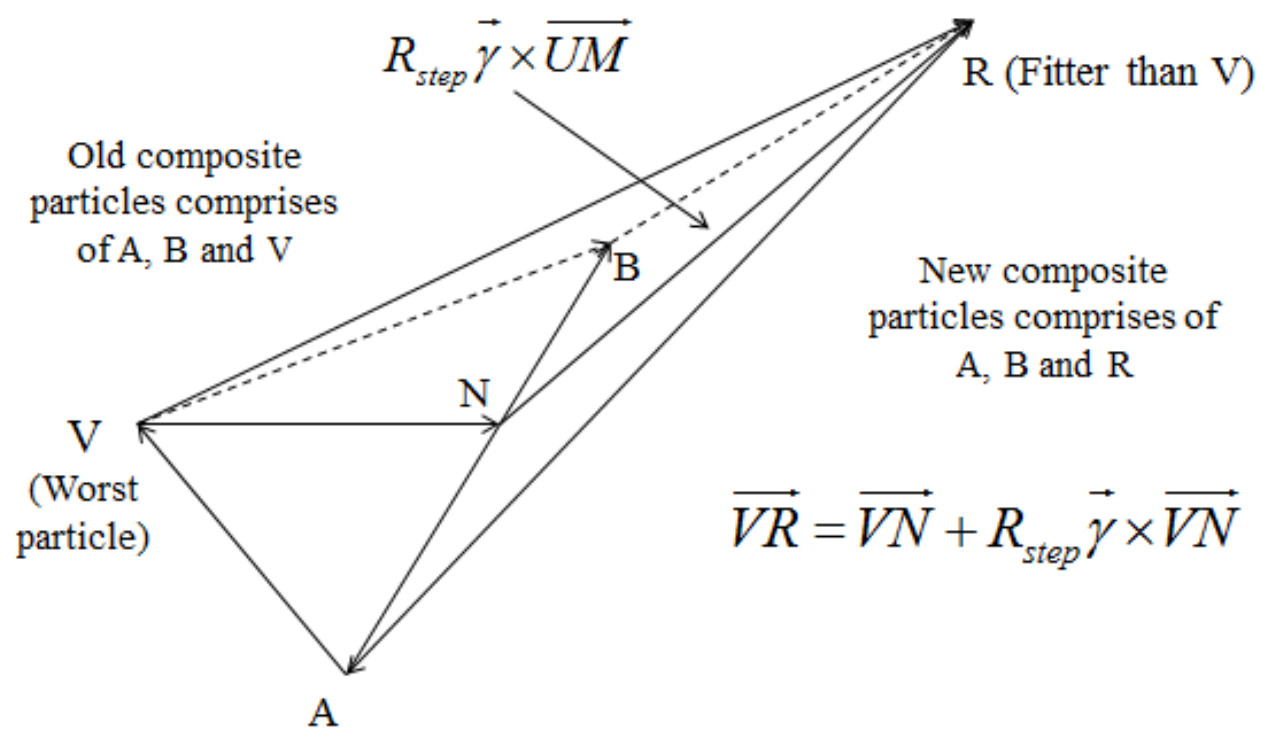

Figure 6. Construction of composite particle using VAR operation 


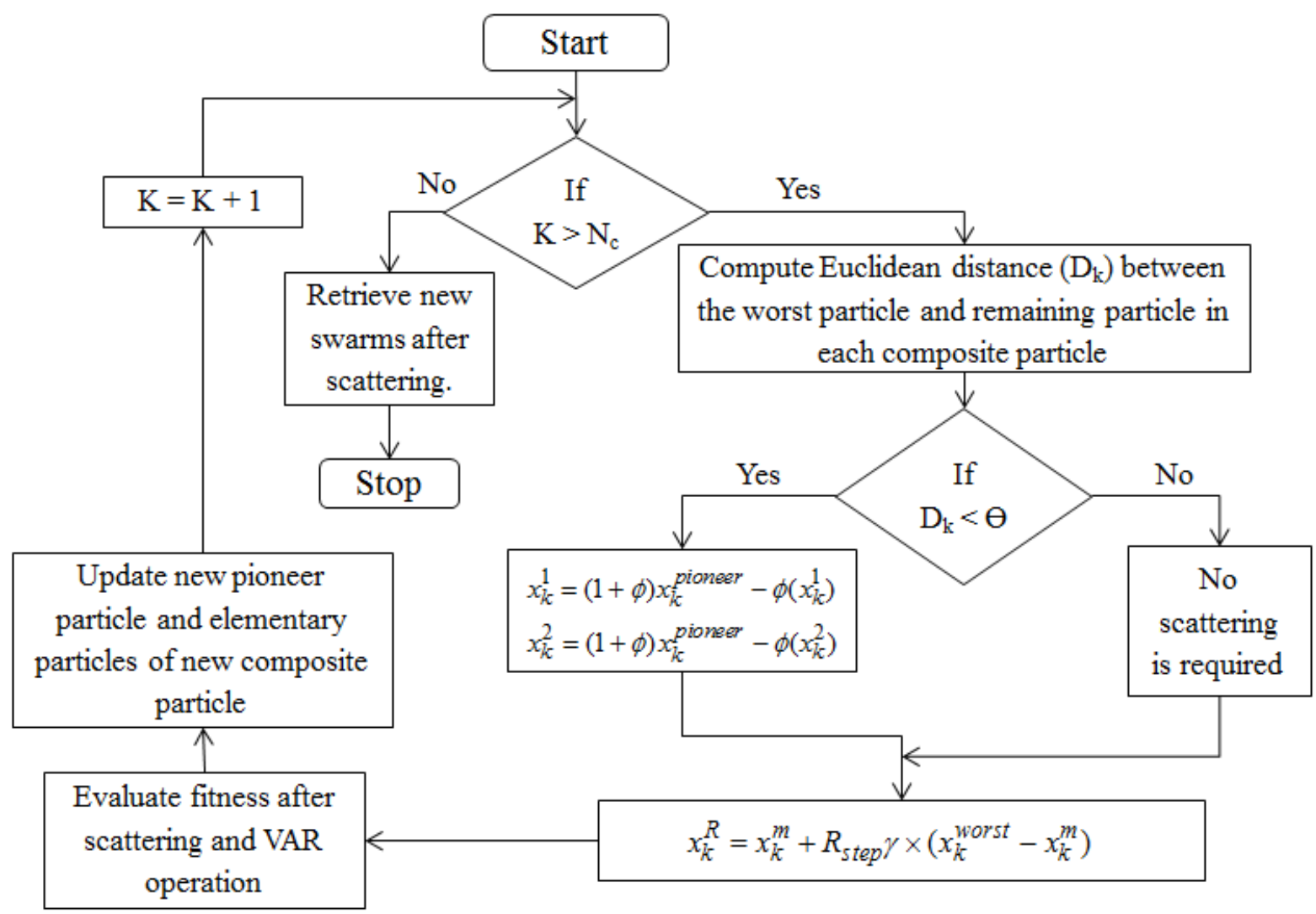

Figure 7: Flowchart depicting the relationship between composite particle, scattering operation and VAR operation.

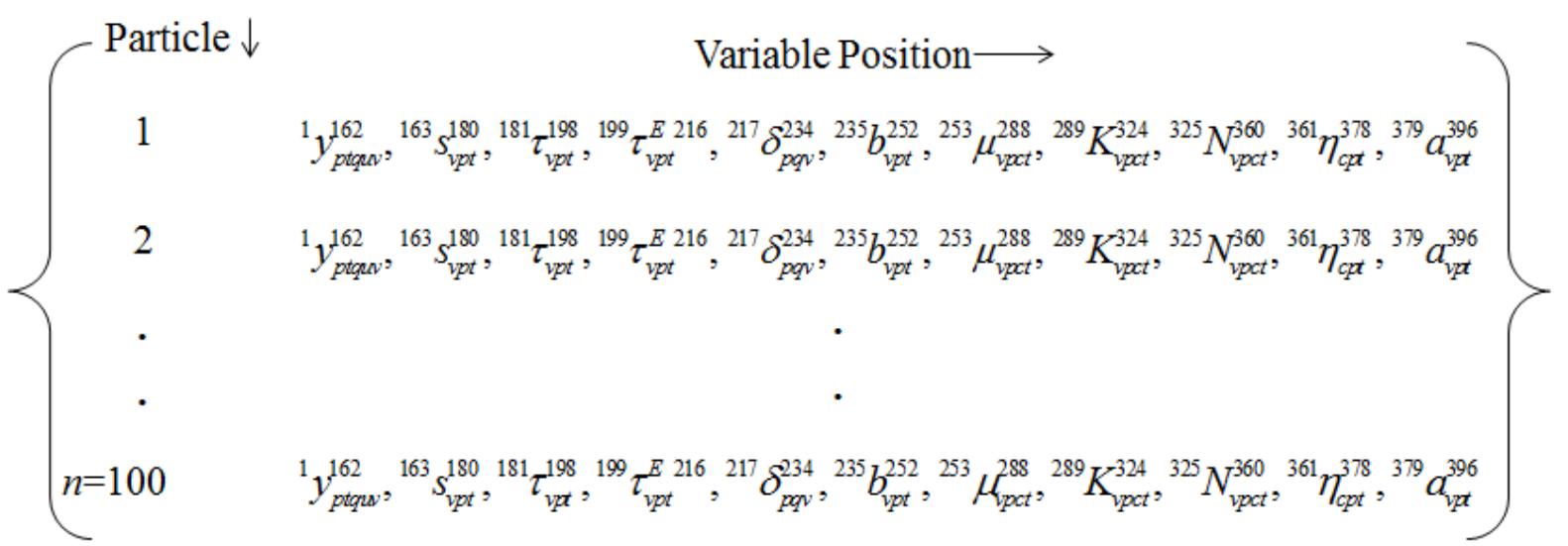

Figure 8. Schematic representation of the swam for a given example 


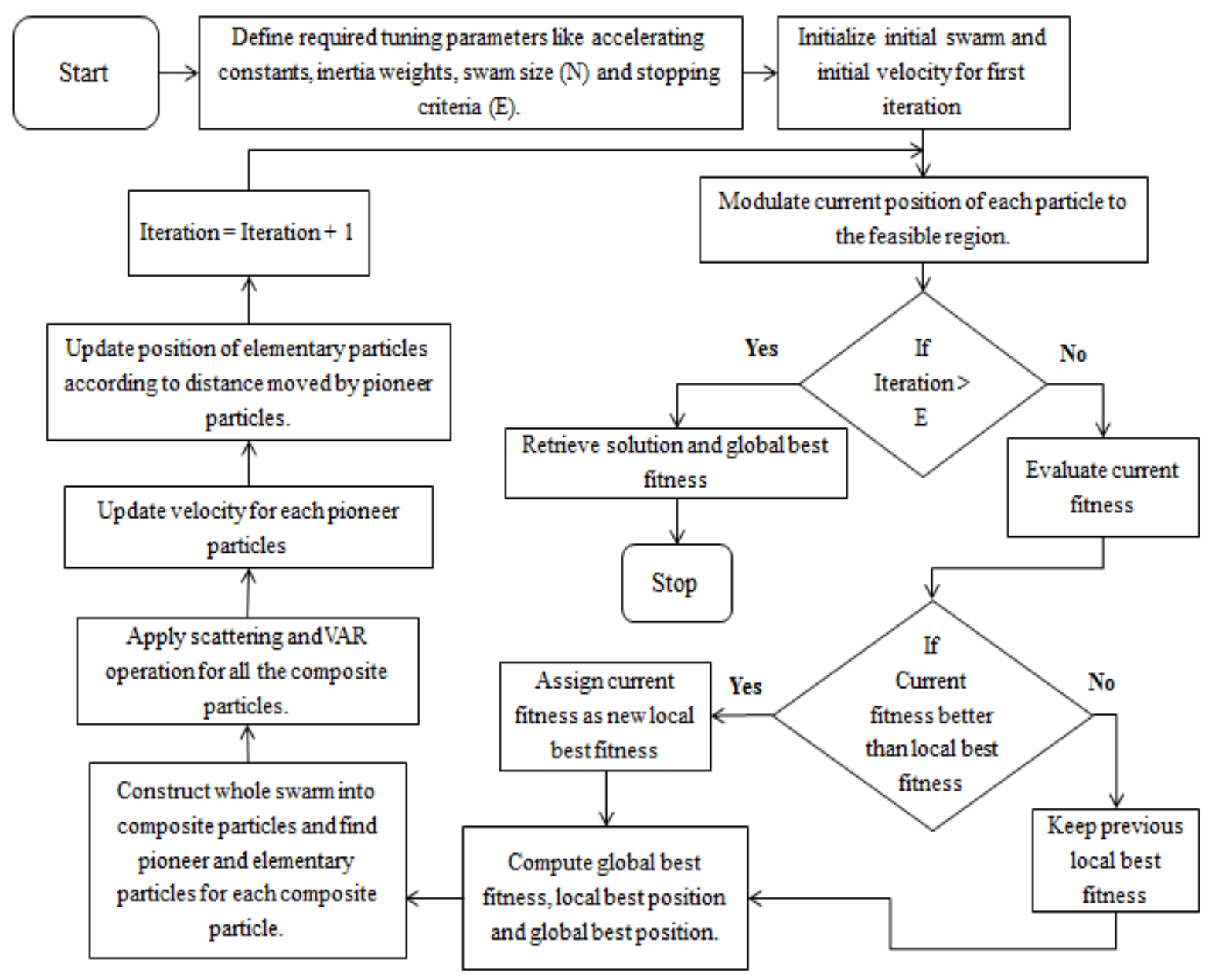

Figure 9. Depicting the flowchart for Particle Swarm Optimization-Composite Particle 


\section{Function PSO-DE}

$N=$ number of iterations

$I=$ number of particles in a swarm

Dim $=$ number of decision variables in one particle

Tuning parameters for $P S O$ (inertia weight( $w$ ), acceleration coefficients $(\mathrm{Cl}, \mathrm{C} 2))$ are considered Tuning parameters for $D E$ ( $F$ and $C R$ ) are considered.

Two random numbers $r 1$ and $r 2$ are generated

\section{Initialization}

Initialize all the particles in a swarm $X_{1}$

Initialize $P_{-}$Best as the current position of the swarm and best position of $P_{-}$Best as $G_{-}$Best

\section{Iterations}

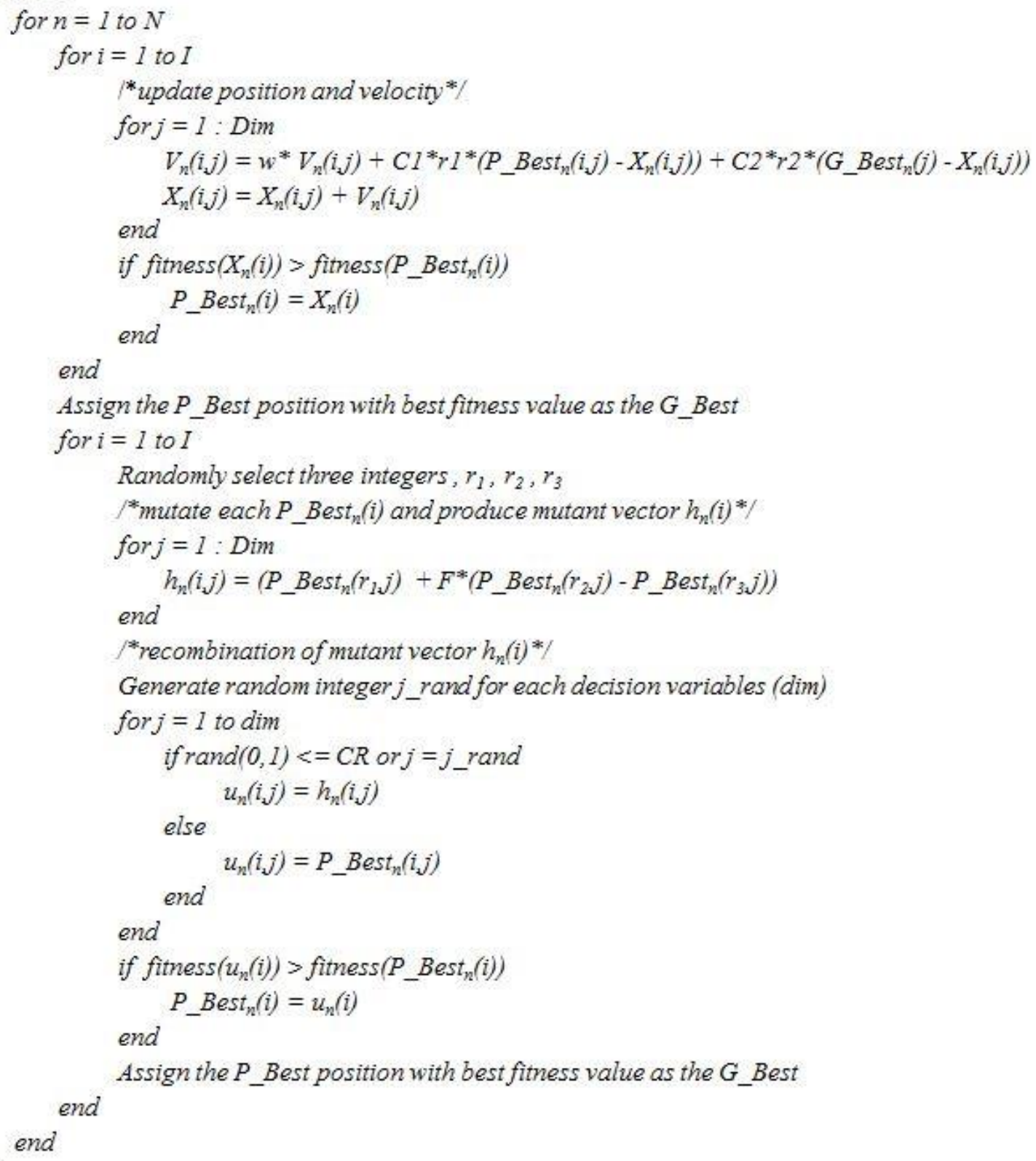

Figure 10: Pseudo code of PSO-DE algorithm 


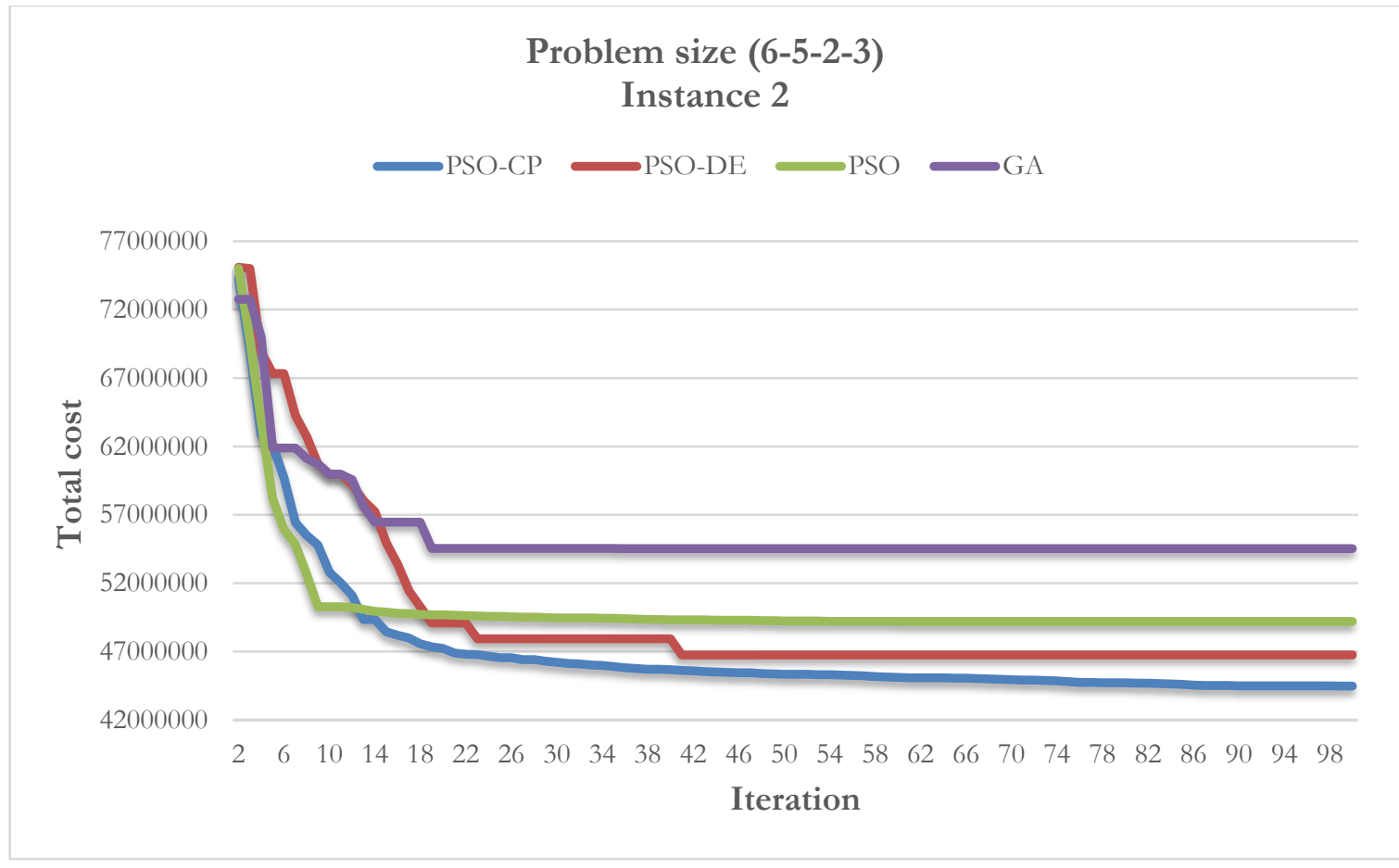

Figure 11: Convergence graph for instance 2 of problem size $(6,5,2,3)$

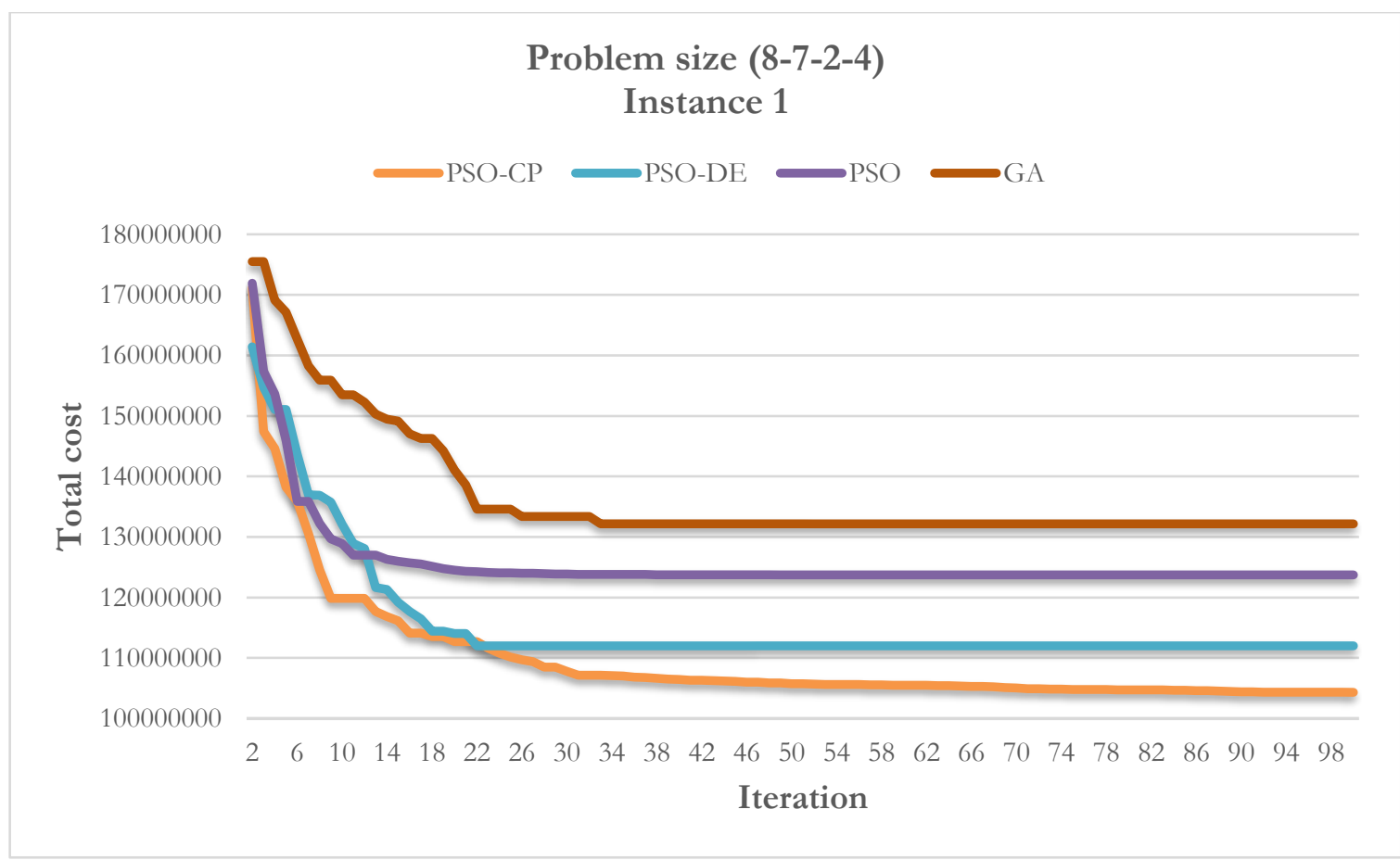

Figure 12: Convergence graph for instance 1 of problem size $(8,7,2,4)$ 
Table 1. Swarm representation

\begin{tabular}{|c|c|c|}
\hline Variable & Variable Structure & $\begin{array}{c}\text { Number of Variables } \\
\text { Considered }\end{array}$ \\
\hline$y_{\text {ptquv }}$ & $\underbrace{y_{11111,} y_{21111,} y_{31111, \ldots \ldots \ldots \ldots . . .} y_{33332}}_{\text {binary } \text { variables }}$ & $\begin{array}{l}p \times t \times q \times u \times v \\
=3 \times 3 \times 3 \times 3 \times 2 \\
=162\end{array}$ \\
\hline$s_{v p t}$ & $\underbrace{S_{111,} S_{121}, S_{131,} \ldots \ldots \ldots . S_{233}}_{\text {binary variables }}$ & $\begin{array}{l}p \times t \times v \\
3 \times 3 \times 2=18\end{array}$ \\
\hline$a_{v p t}$ & $\underbrace{a_{111}, a_{121}, a_{131}, \ldots \ldots . a_{233}}_{\text {continuous variables }}$ & $3 \times 3 \times 2=18$ \\
\hline$\tau_{v p t}$ & $\underbrace{\tau_{111}, \tau_{121}, \tau_{131}, \ldots \ldots . \tau_{233}}_{\text {continuous variables }}$ & $3 \times 3 \times 2=18$ \\
\hline$\overline{\tau_{v p t}^{E}}$ & $\underbrace{\tau_{111}^{E}, \tau_{121}^{E}, \tau_{131}^{E}, \ldots \ldots . \tau_{233}^{E}}_{\text {continuous variables }}$ & $3 \times 3 \times 2=18$ \\
\hline$\delta_{p q v}$ & $\underbrace{\delta_{111}, \delta_{211}, \delta_{311}, \ldots \ldots \delta_{233}}_{\text {continuous variables }}$ & $3 \times 3 \times 2=18$ \\
\hline$b_{v p t}$ & $\underbrace{b_{111}, b_{121}, b_{131}, \ldots \ldots b_{233}}_{\text {continuous variables }}$ & $3 \times 3 \times 2=18$ \\
\hline$\mu_{v p c t}$ & $\underbrace{\mu_{1111}, \mu_{1211}, \mu_{1311}, \ldots \ldots . \mu_{2323}}_{\text {binary variables }}$ & $3 \times 3 \times 2 \times 2=36$ \\
\hline$K_{v p c t}$ & $\underbrace{K_{1111}, K_{1211}, K_{1311}, \ldots \ldots . K_{2323}}_{\text {continuous vari ables }}$ & $3 \times 3 \times 2 \times 2=36$ \\
\hline$N_{v p c t}$ & $\underbrace{N_{1111}, N_{1211}, N_{1311}, \ldots \ldots . . N_{2323}}_{\text {continuous variables }}$ & $3 \times 3 \times 2 \times 2=36$ \\
\hline$\eta_{c p t}$ & $\underbrace{\eta_{111}, \eta_{121}, \eta_{131}, \ldots \ldots . \eta_{233}}_{\text {continuous variables }}$ & $3 \times 3 \times 2=18$ \\
\hline
\end{tabular}


Table 2. Depicting the different problem sizes considered for experimental purpose

\begin{tabular}{|c|c|c|c|c|}
\hline Serial No. & $\begin{array}{c}\text { Problem Size } \\
\text { (ports, periods, } \\
\text { containers, ships) }\end{array}$ & $\begin{array}{c}\text { Number of } \\
\text { variables }\end{array}$ & $\begin{array}{c}\text { Number of } \\
\text { equality } \\
\text { constraints }\end{array}$ & $\begin{array}{c}\text { Number of } \\
\text { inequality } \\
\text { constraints }\end{array}$ \\
\hline 1 & $(3,3,2,2)$ & 396 & 400 & 405 \\
\hline 2 & $(4,4,2,2)$ & 928 & 1156 & 944 \\
\hline 3 & $(6,5,2,3)$ & 3888 & 5754 & 3888 \\
\hline 4 & $(8,7,2,4)$ & 15488 & 25912 & 15432 \\
\hline 5 & $(9,10,2,5)$ & 46305 & 82495 & 46125 \\
\hline 6 & $(10,16,2,6)$ & 165720 & 310052 & 165240 \\
\hline 7 & $(10,22,2,6)$ & 306840 & 584492 & 306180 \\
\hline
\end{tabular}

Table 3. Depicting the data set for the computational purpose

\begin{tabular}{|c|c|c|}
\hline Parameter or variable & Range & Units \\
\hline$R_{c p}$ & $(500,1000)$ & USD/operation \\
\hline$R_{p t}^{E}$ & $(100,500)$ & USD/hour \\
\hline$R_{p t}^{S}$ & $(100,500)$ & USD/hour \\
\hline$R_{p t}^{F}$ & $(50,100)$ & USD/hour \\
\hline$f_{p v}$ & $(20,40)$ & Tonnes/hour \\
\hline$B_{p t}^{S}$ & $(6,9)$ & Hours (real time) \\
\hline$B_{p t}^{E}$ & $(18,20)$ & Hours (real time) \\
\hline$A_{p t v}$ & $(5,6)$ & Hours (real time) \\
\hline$a_{p t v}, a_{p t v}$ & $(4,8)$ & Hours per container \\
\hline$\beta_{p c}$ & $(0.2,0.3)$ & Hours per operation \\
\hline$\alpha_{p c}$ & $(0.5,1)$ & Nautical miles (nm) \\
\hline$L_{p q}$ & $(500,800)$ & Units \\
\hline$D_{c p t}$ & $(400,800)$ & Units \\
\hline$\lambda_{p c}$ & $(300,400)$ & Berths \\
\hline$\theta_{p}$ & $(3,5)$ & \\
\hline & & \\
\hline
\end{tabular}


Table 4. Initial ship position for every problem size

\begin{tabular}{|c|c|c|c|c|}
\hline $\begin{array}{c}\text { Problem Size } \\
\text { (ports, periods, } \\
\text { containers, ships) }\end{array}$ & $\begin{array}{c}\text { Ship } \\
\text { number }\end{array}$ & Instance 1 & Instance 2 & Instance 3 \\
\hline \multirow{2}{*}{$(3,3,2,2)$} & Ship 1 & $y_{11 q u 1}$ & $y_{21 q u 1}$ & $y_{11 q u 1}$ \\
\hline & Ship 2 & $y_{11 q u 2}$ & $y_{11 q u 2}$ & $y_{31 q u 2}$ \\
\hline \multirow{2}{*}{$(4,4,2,2)$} & Ship 1 & $y_{11 q u 1}$ & $y_{11 q u 1}$ & $y_{21 q u 1}$ \\
\hline & Ship 2 & $y_{21 q u 2}$ & $y_{21 q u 2}$ & $y_{31 q u 2}$ \\
\hline \multirow{3}{*}{$(6,5,2,3)$} & Ship 1 & $y_{21 q u 1}$ & $y_{31 q u 1}$ & $y_{11 q u 1}$ \\
\hline & Ship 2 & $y_{11 q u 2}$ & $y_{51 q u 2}$ & $y_{41 q u 2}$ \\
\hline & Ship 3 & $y_{11 q u 3}$ & $y_{31 q u 3}$ & $y_{11 q u 3}$ \\
\hline \multirow{4}{*}{$(8,7,2,4)$} & Ship 1 & $y_{11 q u 1}$ & $y_{31 q u 1}$ & $y_{41 q u 1}$ \\
\hline & Ship 2 & $y_{21 q u 2}$ & $y_{41 q u 2}$ & $y_{51 q u 2}$ \\
\hline & Ship 3 & $y_{21 q u 3}$ & $y_{31 q u 3}$ & $y_{21 q u 3}$ \\
\hline & Ship 4 & $y_{41 q u 4}$ & $y_{11 q u 4}$ & $y_{11 q u 4}$ \\
\hline \multirow{5}{*}{$(9,10,2,5)$} & Ship 1 & $y_{31 q u 1}$ & $y_{21 q u 1}$ & $y_{61 q u 1}$ \\
\hline & Ship 2 & $y_{51 q u 2}$ & $y_{41 q u 2}$ & $y_{21 q u 2}$ \\
\hline & Ship 3 & $y_{41 q u 3}$ & $y_{61 q u 3}$ & $y_{51 q u 3}$ \\
\hline & Ship 4 & $y_{11 q u 4}$ & $y_{31 q u 4}$ & $y_{21 q u 4}$ \\
\hline & Ship 5 & $y_{11 q u 5}$ & $y_{51 q u 5}$ & $y_{31 q u 5}$ \\
\hline \multirow{6}{*}{$(10,16,2,6)$} & Ship 1 & $y_{41 q u 1}$ & $y_{21 q u 1}$ & $y_{11 q u 1}$ \\
\hline & Ship 2 & $y_{11 q u 2}$ & $y_{31 q u 2}$ & $y_{21 q u 2}$ \\
\hline & Ship 3 & $y_{11 q u 3}$ & $y_{51 q u 3}$ & $y_{41 q u 3}$ \\
\hline & Ship 4 & $y_{11 q u 4}$ & $y_{41 q u 4}$ & $y_{51 q u 4}$ \\
\hline & Ship 5 & $y_{21 q u 5}$ & $y_{11 q u 5}$ & $y_{41 q u 5}$ \\
\hline & Ship 6 & $y_{51 q u 6}$ & $y_{21 q u 6}$ & $y_{21 q u 6}$ \\
\hline \multirow{6}{*}{$(10,22,2,6)$} & Ship 1 & $y_{11 q u 1}$ & $y_{31 q u 1}$ & $y_{51 q u 1}$ \\
\hline & Ship 2 & $y_{51 q u 2}$ & $y_{41 q u 2}$ & $y_{41 q u 2}$ \\
\hline & Ship 3 & $y_{21 q u 3}$ & $y_{21 q u 3}$ & $y_{11 q u 3}$ \\
\hline & Ship 4 & $y_{51 q u 4}$ & $y_{31 q u 4}$ & $y_{21 q u 4}$ \\
\hline & Ship 5 & $y_{31 q u 5}$ & $y_{11 q u 5}$ & $y_{41 q u 5}$ \\
\hline & Ship 6 & $y_{11 q u 6}$ & $y_{51 q u 6}$ & $y_{31 q u 6}$ \\
\hline
\end{tabular}


Table 5. Optimal values of the parameters considered for the experiment

\begin{tabular}{|c|c|c|c|c|c|c|c|}
\hline Parameter & $\begin{array}{c}\text { Inertia } \\
\text { Weight }\end{array}$ & \multicolumn{2}{|c|}{$\begin{array}{c}\text { Acceleration } \\
\text { coefficients }\end{array}$} & $\begin{array}{c}\text { Diversification } \\
\text { Parameter used in } \\
\text { VAR operation }\end{array}$ & Stretching parameters & $\begin{array}{c}\text { Euclidean } \\
\text { distance } \\
\text { limit }\end{array}$ \\
\hline Setting & 0.9 & 0.1 & 0.98 & 6 & 2 & 3 & 0.5 \\
\hline
\end{tabular}

Table 6. Computational results for instances 1 of all the problem sizes

\begin{tabular}{|c|c|c|c|c|c|}
\hline Problem size & Algorithm & Best solution & Worst solution & Mean & $\begin{array}{l}\text { Standard } \\
\text { deviation }\end{array}$ \\
\hline \multirow{4}{*}{$\begin{array}{l}(3,3,2,2) \\
\text { Instance } 1\end{array}$} & PSO-CP & $7.566 \times 10^{6}$ & $8.456 \times 10^{6}$ & $7.961 \times 10^{6}$ & $5.981 \times 10^{5}$ \\
\hline & PSO-DE & $8.351 \times 10^{6}$ & $9.338 \times 10^{6}$ & $8.974 \times 10^{6}$ & $6.676 \times 10^{5}$ \\
\hline & PSO & $8.681 \times 10^{6}$ & $1.141 \times 10^{7}$ & $9.435 \times 10^{6}$ & $6.944 \times 10^{5}$ \\
\hline & GA & $8.859 \times 10^{6}$ & $1.084 \times 10^{7}$ & $9.669 \times 10^{6}$ & $7.173 \times 10^{5}$ \\
\hline \multirow{4}{*}{$\begin{array}{l}(4,4,2,2) \\
\text { Instance } 1\end{array}$} & PSO-CP & $1.488 \times 10^{7}$ & $1.579 \times 10^{7}$ & $1.508 \times 10^{7}$ & $6.152 \times 10^{5}$ \\
\hline & PSO-DE & $1.497 \times 10^{7}$ & $1.808 \times 10^{7}$ & $1.614 \times 10^{7}$ & $7.312 \times 10^{5}$ \\
\hline & PSO & $1.525 \times 10^{7}$ & $1.821 \times 10^{7}$ & $1.663 \times 10^{7}$ & $8.704 \times 10^{5}$ \\
\hline & GA & $1.731 \times 10^{7}$ & $2.063 \times 10^{7}$ & $1.797 \times 10^{7}$ & $8.528 \times 10^{5}$ \\
\hline \multirow{4}{*}{$\begin{array}{l}(6,5,2,3) \\
\text { Instance } 1\end{array}$} & PSO-CP & $3.661 \times 10^{7}$ & $3.853 \times 10^{7}$ & $3.702 \times 10^{7}$ & $2.457 \times 10^{6}$ \\
\hline & PSO-DE & $4.216 \times 10^{7}$ & $4.838 \times 10^{7}$ & $4.686 \times 10^{7}$ & $3.112 \times 10^{6}$ \\
\hline & PSO & $5.061 \times 10^{7}$ & $5.301 \times 10^{7}$ & $5.172 \times 10^{7}$ & $3.354 \times 10^{6}$ \\
\hline & GA & $5.879 \times 10^{7}$ & $6.193 \times 10^{7}$ & $5.966 \times 10^{7}$ & $3.268 \times 10^{6}$ \\
\hline \multirow{4}{*}{$\begin{array}{l}(8,7,2,4) \\
\text { Instance } 1\end{array}$} & $\begin{array}{l}\text { PSO-CP } \\
\text { PSO }\end{array}$ & $1.043 \times 10^{8}$ & $1.102 \times 10^{8}$ & $1.095 \times 10^{8}$ & $6.464 \times 10^{6}$ \\
\hline & PSO-DE & $1.120 \times 10^{8}$ & $1.292 \times 10^{8}$ & $1.188 \times 10^{8}$ & $7.995 \times 10^{6}$ \\
\hline & PSO & $1.237 \times 10^{8}$ & $1.378 \times 10^{8}$ & $1.322 \times 10^{8}$ & $8.032 \times 10^{6}$ \\
\hline & GA & $1.321 \times 10^{8}$ & $1.496 \times 10^{8}$ & $1.431 \times 10^{8}$ & $8.436 \times 10^{6}$ \\
\hline \multirow{4}{*}{$\begin{array}{c}(9,10,2,5) \\
\text { Instance } 1\end{array}$} & PSO-CP & $4.497 \times 10^{8}$ & $4.639 \times 10^{8}$ & $4.502 \times 10^{8}$ & $2.013 \times 10^{7}$ \\
\hline & PSO-DE & $4.605 \times 10^{8}$ & $4.871 \times 10^{8}$ & $4.693 \times 10^{8}$ & $2.408 \times 10^{7}$ \\
\hline & PSO & $5.204 \times 10^{8}$ & $5.630 \times 10^{8}$ & $5.402 \times 10^{8}$ & $2.878 \times 10^{7}$ \\
\hline & GA & $5.561 \times 10^{8}$ & $6.022 \times 10^{8}$ & $5.897 \times 10^{8}$ & $3.141 \times 10^{7}$ \\
\hline \multirow{4}{*}{$\begin{array}{c}(10,16,2,6) \\
\text { Instance } 1\end{array}$} & PSO-CP & $9.483 \times 10^{8}$ & $9.928 \times 10^{9}$ & $9.769 \times 10^{8}$ & $2.955 \times 10^{7}$ \\
\hline & PSO-DE & $1.026 \times 10^{9}$ & $1.358 \times 10^{9}$ & $1.085 \times 10^{9}$ & $3.794 \times 10^{7}$ \\
\hline & PSO & $1.061 \times 10^{9}$ & $1.567 \times 10^{9}$ & $1.132 \times 10^{9}$ & $4.106 \times 10^{7}$ \\
\hline & GA & $1.248 \times 10^{9}$ & $1.831 \times 10^{9}$ & $1.344 \times 10^{9}$ & $4.548 \times 10^{7}$ \\
\hline \multirow{4}{*}{$\begin{array}{c}(10,22,2,6) \\
\text { Instance } 1\end{array}$} & PSO-CP & $2.691 \times 10^{9}$ & $3.076 \times 10^{9}$ & $2.805 \times 10^{9}$ & $7.784 \times 10^{7}$ \\
\hline & PSO-DE & $3.099 \times 10^{9}$ & $3.385 \times 10^{9}$ & $3.231 \times 10^{9}$ & $8.117 \times 10^{7}$ \\
\hline & PSO & $3.587 \times 10^{9}$ & $3.928 \times 10^{9}$ & $3.696 \times 10^{9}$ & $8.763 \times 10^{7}$ \\
\hline & GA & $3.737 \times 10^{9}$ & $4.120 \times 10^{9}$ & $3.884 \times 10^{9}$ & $9.291 \times 10^{7}$ \\
\hline
\end{tabular}


Table 7. Computational time required for solving all the instances of each problem using different algorithms

\begin{tabular}{|c|c|c|c|c|c|c|c|c|c|c|c|c|}
\hline \multirow{2}{*}{$\begin{array}{l}\text { Problem Size } \\
\text { (ports, } \\
\text { periods, } \\
\text { containers, } \\
\text { ships) }\end{array}$} & \multicolumn{4}{|c|}{ Instance 1} & \multicolumn{4}{|c|}{ Instance 2} & \multicolumn{4}{|c|}{ Instance 3} \\
\hline & $\begin{array}{c}\text { PSO-CP } \\
\text { (sec) }\end{array}$ & $\begin{array}{c}\text { PSO-DE } \\
\quad(\mathrm{sec})\end{array}$ & $\begin{array}{l}\text { PSO } \\
(\mathrm{sec})\end{array}$ & $\begin{array}{c}\text { GA } \\
(\mathrm{sec})\end{array}$ & $\begin{array}{c}\text { PSO-CP } \\
\quad(\mathrm{sec})\end{array}$ & $\begin{array}{l}\text { PSO-DE } \\
\quad(\mathrm{sec})\end{array}$ & $\begin{array}{l}\text { PSO } \\
(\mathrm{sec})\end{array}$ & $\begin{array}{c}\text { GA } \\
(\mathrm{sec})\end{array}$ & $\begin{array}{l}\text { PSO-CP } \\
(\mathrm{sec})\end{array}$ & $\begin{array}{l}\text { PSO-DE } \\
\quad(\mathrm{sec})\end{array}$ & $\begin{array}{l}\text { PSO } \\
(\mathrm{sec})\end{array}$ & $\begin{array}{c}\text { GA } \\
(\mathrm{sec})\end{array}$ \\
\hline$(3,3,2,2)$ & 94.7 & 87.6 & 77.8 & 84.8 & 94.9 & 87.0 & 76.3 & 84.5 & 95.1 & 86.8 & 74.4 & 84.2 \\
\hline$(4,4,2,2)$ & 141.7 & 129.1 & 111.2 & 121.8 & 143.4 & 131.6 & 113.9 & 123.5 & 142.2 & 128.1 & 112.8 & 121.5 \\
\hline$(6,5,2,3)$ & 175.3 & 171.6 & 151.3 & 168.4 & 176.68 & 170.2 & 148.4 & 165.2 & 176.7 & 173.50 & 146 & 164.2 \\
\hline$(8,7,2,4)$ & 253.2 & 241.3 & 221.8 & 236.7 & 251.4 & 241.7 & 218.2 & 231.3 & 250.9 & 239.92 & 219.1 & 230.7 \\
\hline$(9,10,2,5)$ & 513.6 & 508.8 & 455.4 & 468.8 & 514.2 & 505.3 & 454.3 & 463.7 & 513.8 & 505.28 & 456.5 & 469.2 \\
\hline$(10,16,2,6)$ & 786.8 & 750.4 & 627.5 & 678.2 & 754.9 & 736.9 & 629.1 & 675.6 & 756.2 & 739.5 & 630.7 & 668.9 \\
\hline$(10,22,2,6)$ & 1252.7 & 1248.2 & 1166.8 & 1192.3 & 1244.1 & 1231.2 & 1164.2 & 1198.6 & 1235.6 & 1226.5 & 1157.8 & 1191.2 \\
\hline
\end{tabular}


Table 8. Table showing the total cost and penalty cost for violating the time window for each instance of every problem

\begin{tabular}{|c|c|c|c|c|c|c|}
\hline \multirow{2}{*}{$\begin{array}{l}\text { Problem Size } \\
\text { (ports, periods, } \\
\text { containers, ships) and } \\
\text { Algorithm used to solve }\end{array}$} & \multicolumn{2}{|c|}{ Instance 1} & \multicolumn{2}{|c|}{ Instance 2} & \multicolumn{2}{|c|}{ Instance 3} \\
\hline & $\begin{array}{c}\text { Total Cost } \\
\text { (USD) }\end{array}$ & $\begin{array}{l}\text { Penalty cost for } \\
\text { violating time } \\
\text { window (USD) }\end{array}$ & $\begin{array}{l}\text { Total Cost } \\
\text { (USD) }\end{array}$ & $\begin{array}{l}\text { Penalty cost for } \\
\text { violating time } \\
\text { window (USD) }\end{array}$ & $\begin{array}{l}\text { Total Cost } \\
\text { (USD) }\end{array}$ & $\begin{array}{l}\text { Penalty cost for } \\
\text { violating time } \\
\text { window (USD) }\end{array}$ \\
\hline$(3,3,2,2)$ PSO-CP & $7.566 \times 10^{6}$ & $1.467 \times 10^{3}$ & $7.754 \times 10^{6}$ & $1.561 \times 10^{3}$ & $7.747 \times 10^{6}$ & $1.285 \times 10^{3}$ \\
\hline$(3,3,2,2)$ PSO-DE & $8.351 \times 10^{6}$ & $3.719 \times 10^{3}$ & $8.943 \times 10^{6}$ & $3.664 \times 10^{3}$ & $8.769 \times 10^{6}$ & $3.256 \times 10^{3}$ \\
\hline$(3,3,2,2) \mathrm{PSO}$ & $8.681 \times 10^{6}$ & $4.132 \times 10^{3}$ & $9.575 \times 10^{6}$ & $4.176 \times 10^{3}$ & $9.575 \times 10^{6}$ & $3.921 \times 10^{3}$ \\
\hline$(3,3,2,2) \mathrm{GA}$ & $8.859 \times 10^{6}$ & $4.347 \times 10^{3}$ & $9.971 \times 10^{6}$ & $4.482 \times 10^{3}$ & $9.886 \times 10^{6}$ & $4.336 \times 10^{3}$ \\
\hline$(4,4,2,2)$ PSO-CP & $1.488 \times 10^{7}$ & $2.811 \times 10^{3}$ & $1.408 \times 10^{7}$ & $2.963 \times 10^{3}$ & $1.269 \times 10^{7}$ & $2.865 \times 10^{3}$ \\
\hline$(4,4,2,2)$ PSO-DE & $1.497 \times 10^{7}$ & $4.853 \times 10^{3}$ & $1.544 \times 10^{7}$ & $5.135 \times 10^{3}$ & $1.498 \times 10^{7}$ & $4.596 \times 10^{3}$ \\
\hline$(4,4,2,2) \mathrm{PSO}$ & $1.525 \times 10^{7}$ & $6.883 \times 10^{3}$ & $1.612 \times 10^{7}$ & $6.091 \times 10^{3}$ & $1.562 \times 10^{7}$ & $7.336 \times 10^{3}$ \\
\hline$(4,4,2,2) \mathrm{GA}$ & $1.731 \times 10^{7}$ & $7.042 \times 10^{3}$ & $1.758 \times 10^{7}$ & $6.821 \times 10^{3}$ & $1.693 \times 10^{7}$ & $7.767 \times 10^{3}$ \\
\hline$(6,5,2,3)$ PSO-CP & $3.661 \times 10^{7}$ & $5.195 \times 10^{3}$ & $4.488 \times 10^{7}$ & $4.924 \times 10^{3}$ & $3.661 \times 10^{7}$ & $5.738 \times 10^{3}$ \\
\hline$(6,5,2,3)$ PSO-DE & $4.216 \times 10^{7}$ & $6.789 \times 10^{3}$ & $4.676 \times 10^{7}$ & $7.931 \times 10^{3}$ & $4.718 \times 10^{7}$ & $7.451 \times 10^{3}$ \\
\hline$(6,5,2,3)$ PSO & $5.061 \times 10^{7}$ & $9.643 \times 10^{3}$ & $4.921 \times 10^{7}$ & $9.611 \times 10^{3}$ & $4.957 \times 10^{7}$ & $9.211 \times 10^{3}$ \\
\hline$(6,5,2,3) \mathrm{GA}$ & $5.879 \times 10^{7}$ & $9.885 \times 10^{3}$ & $5.726 \times 10^{7}$ & $9.542 \times 10^{3}$ & $5.434 \times 10^{7}$ & $9.542 \times 10^{3}$ \\
\hline$(8,7,2,4)$ PSO-CP & $1.043 \times 10^{8}$ & $4.752 \times 10^{3}$ & $1.052 \times 10^{8}$ & $4.521 \times 10^{3}$ & $9.931 \times 10^{7}$ & $5.395 \times 10^{3}$ \\
\hline$(8,7,2,4)$ PSO-DE & $1.120 \times 10^{8}$ & $7.317 \times 10^{3}$ & $1.120 \times 10^{8}$ & $6.586 \times 10^{3}$ & $1.048 \times 10^{8}$ & $7.452 \times 10^{3}$ \\
\hline$(8,7,2,4) \mathrm{PSO}$ & $1.237 \times 10^{8}$ & $7.908 \times 10^{3}$ & $1.231 \times 10^{8}$ & $7.425 \times 10^{3}$ & $1.194 \times 10^{8}$ & $8.234 \times 10^{3}$ \\
\hline$(8,7,2,4) \mathrm{GA}$ & $1.321 \times 10^{8}$ & $8.372 \times 10^{3}$ & $1.346 \times 10^{8}$ & $8.108 \times 10^{3}$ & $1.363 \times 10^{8}$ & $8.890 \times 10^{3}$ \\
\hline$(9,10,2,5)$ PSO-CP & $4.497 \times 10^{8}$ & $8.454 \times 10^{3}$ & $4.360 \times 10^{8}$ & $8.798 \times 10^{3}$ & $4.291 \times 10^{8}$ & $8.943 \times 10^{3}$ \\
\hline$(9,10,2,5)$ PSO-DE & $4.605 \times 10^{8}$ & $9.795 \times 10^{3}$ & $4.638 \times 10^{8}$ & $1.056 \times 10^{4}$ & $4.960 \times 10^{8}$ & $1.021 \times 10^{4}$ \\
\hline$(9,10,2,5)$ PSO & $5.204 \times 10^{8}$ & $1.457 \times 10^{4}$ & $5.174 \times 10^{8}$ & $1.347 \times 10^{4}$ & $5.222 \times 10^{8}$ & $1.481 \times 10^{4}$ \\
\hline$(9,10,2,5) \mathrm{GA}$ & $5.561 \times 10^{8}$ & $1.623 \times 10^{4}$ & $5.405 \times 10^{8}$ & $1.646 \times 10^{4}$ & $5.619 \times 10^{8}$ & $1.535 \times 10^{4}$ \\
\hline$(10,16,2,6)$ PSO-CP & $9.483 \times 10^{8}$ & $1.552 \times 10^{4}$ & $9.375 \times 10^{8}$ & $1.48 \times 10^{4}$ & $1.008 \times 10^{9}$ & $1.467 \times 10^{4}$ \\
\hline$(10,16,2,6)$ PSO-DE & $1.026 \times 10^{9}$ & $1.967 \times 10^{4}$ & $1.078 \times 10^{9}$ & $2.010 \times 10^{4}$ & $1.042 \times 10^{9}$ & $1.567 \times 10^{4}$ \\
\hline$(10,16,2,6)$ PSO & $1.061 \times 10^{9}$ & $2.348 \times 10^{4}$ & $1.151 \times 10^{9}$ & $2.177 \times 10^{4}$ & $1.097 \times 10^{9}$ & $2.112 \times 10^{4}$ \\
\hline$(10,16,2,6) \mathrm{GA}$ & $1.248 \times 10^{9}$ & $2.662 \times 10^{4}$ & $1.294 \times 10^{9}$ & $2.410 \times 10^{4}$ & $1.304 \times 10^{9}$ & $2.521 \times 10^{4}$ \\
\hline$(10,22,2,6)$ PSO-CP & $2.691 \times 10^{9}$ & $3.784 \times 10^{4}$ & $2.776 \times 10^{9}$ & $3.514 \times 10^{4}$ & $2.829 \times 10^{9}$ & $3.778 \times 10^{4}$ \\
\hline$(10,22,2,6)$ PSO-DE & $3.099 \times 10^{9}$ & $4.159 \times 10^{4}$ & $3.118 \times 10^{9}$ & $3.953 \times 10^{4}$ & $3.176 \times 10^{9}$ & $4.063 \times 10^{4}$ \\
\hline$(10,22,2,6)$ PSO & $3.587 \times 10^{9}$ & $4.621 \times 10^{4}$ & $3.437 \times 10^{9}$ & $4.428 \times 10^{4}$ & $3.592 \times 10^{9}$ & $4.419 \times 10^{4}$ \\
\hline$(10,22,2,6) \mathrm{GA}$ & $3.737 \times 10^{9}$ & $4.878 \times 10^{4}$ & $3.683 \times 10^{9}$ & $4.759 \times 10^{4}$ & $3.778 \times 10^{9}$ & $4.685 \times 10^{4}$ \\
\hline
\end{tabular}


Table 9. Fuel cost incurred at port and sea for each problem instances

\begin{tabular}{|c|c|c|c|c|c|c|c|c|c|}
\hline \multirow{2}{*}{$\begin{array}{l}\text { Problem Size } \\
\text { (ports, periods, } \\
\text { containers, } \\
\text { ships) }\end{array}$} & \multirow[t]{2}{*}{$\begin{array}{l}\text { Problem } \\
\text { instances }\end{array}$} & \multicolumn{4}{|c|}{$\begin{array}{c}\text { Fuel cost incurred at port (USD) } \\
\text { Result obtained using different algorithms }\end{array}$} & \multicolumn{4}{|c|}{$\begin{array}{c}\text { Fuel cost incurred at sea (USD) } \\
\text { Result obtained using different algorithms }\end{array}$} \\
\hline & & PSO-CP & PSO-DE & PSO & GA & PSO-CP & PSO-DE & PSO & GA \\
\hline \multirow{3}{*}{$(3,3,2,2)$} & Instance 1 & $2.190 \times 10^{4}$ & $2.890 \times 10^{4}$ & $3.034 \times 10^{4}$ & $3.092 \times 10^{4}$ & $2.826 \times 10^{6}$ & $3.549 \times 10^{6}$ & $4.098 \times 10^{6}$ & $4.274 \times 10^{6}$ \\
\hline & Instance 2 & $1.894 \times 10^{4}$ & $2.285 \times 10^{4}$ & $2.353 \times 10^{4}$ & $2.309 \times 10^{4}$ & $3.674 \times 10^{6}$ & $4.970 \times 10^{6}$ & $6.077 \times 10^{6}$ & $6.358 \times 10^{6}$ \\
\hline & Instance 3 & $1.881 \times 10^{4}$ & $2.075 \times 10^{4}$ & $2.347 \times 10^{4}$ & $2.427 \times 10^{4}$ & $4.239 \times 10^{6}$ & $5.761 \times 10^{6}$ & $6.077 \times 10^{6}$ & $6.219 \times 10^{6}$ \\
\hline \multirow{3}{*}{$(4,4,2,2)$} & Instance 1 & $5.041 \times 10^{4}$ & $6.449 \times 10^{4}$ & $7.827 \times 10^{4}$ & $7.489 \times 10^{4}$ & $3.243 \times 10^{6}$ & $4.145 \times 10^{6}$ & $4.991 \times 10^{6}$ & $5.176 \times 10^{6}$ \\
\hline & Instance 2 & $5.033 \times 10^{4}$ & $6.478 \times 10^{4}$ & $7.846 \times 10^{4}$ & $7.273 \times 10^{4}$ & $3.395 \times 10^{6}$ & $3.758 \times 10^{6}$ & $4.663 \times 10^{6}$ & $4.934 \times 10^{6}$ \\
\hline & Instance 3 & $5.003 \times 10^{4}$ & $6.637 \times 10^{4}$ & $7.052 \times 10^{4}$ & $7.474 \times 10^{4}$ & $2.120 \times 10^{6}$ & $3.231 \times 10^{6}$ & $4.239 \times 10^{6}$ & $4.619 \times 10^{6}$ \\
\hline \multirow{3}{*}{$(6,5,2,3)$} & Instance 1 & $1.417 \times 10^{5}$ & $2.112 \times 10^{5}$ & $2.874 \times 10^{5}$ & $2.958 \times 10^{5}$ & $2.751 \times 10^{7}$ & $3.043 \times 10^{7}$ & $3.939 \times 10^{7}$ & $4.364 \times 10^{7}$ \\
\hline & Instance 2 & $1.391 \times 10^{5}$ & $1.870 \times 10^{5}$ & $2.682 \times 10^{5}$ & $2.931 \times 10^{5}$ & $2.412 \times 10^{7}$ & $2.859 \times 10^{7}$ & $3.713 \times 10^{7}$ & $4.121 \times 10^{7}$ \\
\hline & Instance 3 & $1.367 \times 10^{5}$ & $1.956 \times 10^{5}$ & $2.732 \times 10^{5}$ & $2.976 \times 10^{5}$ & $2.696 \times 10^{7}$ & $3.124 \times 10^{7}$ & $3.826 \times 10^{7}$ & $4.258 \times 10^{7}$ \\
\hline \multirow{3}{*}{$(8,7,2,4)$} & Instance 1 & $3.127 \times 10^{5}$ & $3.831 \times 10^{5}$ & $4.254 \times 10^{5}$ & $4.828 \times 10^{5}$ & $8.048 \times 10^{7}$ & $8.795 \times 10^{7}$ & $9.736 \times 10^{7}$ & $9.945 \times 10^{7}$ \\
\hline & Instance 2 & $3.164 \times 10^{5}$ & $3.632 \times 10^{5}$ & $4.193 \times 10^{5}$ & $4.891 \times 10^{5}$ & $8.126 \times 10^{7}$ & $8.943 \times 10^{7}$ & $9.657 \times 10^{7}$ & $9.928 \times 10^{7}$ \\
\hline & Instance 3 & $3.055 \times 10^{5}$ & $3.799 \times 10^{5}$ & $4.109 \times 10^{5}$ & $4.976 \times 10^{5}$ & $7.538 \times 10^{7}$ & $8.262 \times 10^{7}$ & $9.382 \times 10^{7}$ & $9.815 \times 10^{7}$ \\
\hline \multirow{3}{*}{$(9,10,2,5)$} & Instance 1 & $6.153 \times 10^{5}$ & $7.299 \times 10^{5}$ & $8.201 \times 10^{5}$ & $8.876 \times 10^{5}$ & $3.927 \times 10^{8}$ & $4.132 \times 10^{8}$ & $4.605 \times 10^{8}$ & $4.712 \times 10^{8}$ \\
\hline & Instance 2 & $6.187 \times 10^{5}$ & $7.271 \times 10^{5}$ & $7.985 \times 10^{5}$ & $8.639 \times 10^{5}$ & $3.782 \times 10^{8}$ & $4.057 \times 10^{8}$ & $4.575 \times 10^{8}$ & $4.691 \times 10^{8}$ \\
\hline & Instance 3 & $6.164 \times 10^{5}$ & $7.398 \times 10^{5}$ & $7.946 \times 10^{5}$ & $8.740 \times 10^{5}$ & $3.716 \times 10^{8}$ & $4.094 \times 10^{8}$ & $4.610 \times 10^{8}$ & $4.694 \times 10^{8}$ \\
\hline \multirow{3}{*}{$(10,16,2,6)$} & Instance 1 & $7.014 \times 10^{5}$ & $8.492 \times 10^{5}$ & $9.268 \times 10^{5}$ & $9.784 \times 10^{5}$ & $8.701 \times 10^{8}$ & $9.382 \times 10^{8}$ & $9.777 \times 10^{8}$ & $9.846 \times 10^{8}$ \\
\hline & Instance 2 & $7.347 \times 10^{5}$ & $8.549 \times 10^{5}$ & $9.316 \times 10^{5}$ & $9.846 \times 10^{5}$ & $8.598 \times 10^{8}$ & $9.756 \times 10^{8}$ & $1.068 \times 10^{9}$ & $1.095 \times 10^{9}$ \\
\hline & Instance 3 & $7.264 \times 10^{5}$ & $8.372 \times 10^{5}$ & $9.185 \times 10^{5}$ & $9.922 \times 10^{5}$ & $9.319 \times 10^{8}$ & $9.871 \times 10^{8}$ & $1.016 \times 10^{9}$ & $1.043 \times 10^{9}$ \\
\hline \multirow{3}{*}{$(10,22,2,6)$} & Instance 1 & $1.778 \times 10^{6}$ & $2.512 \times 10^{6}$ & $2.829 \times 10^{6}$ & $3.651 \times 10^{6}$ & $2.252 \times 10^{9}$ & $2.647 \times 10^{9}$ & $3.047 \times 10^{9}$ & $3.134 \times 10^{9}$ \\
\hline & Instance 2 & $2.126 \times 10^{6}$ & $2.653 \times 10^{6}$ & $3.094 \times 10^{6}$ & $3.860 \times 10^{6}$ & $2.336 \times 10^{9}$ & $2.721 \times 10^{9}$ & $2.982 \times 10^{9}$ & $3.179 \times 10^{9}$ \\
\hline & Instance 3 & $1.837 \times 10^{6}$ & $2.504 \times 10^{6}$ & $2.903 \times 10^{6}$ & $3.504 \times 10^{6}$ & $2.343 \times 10^{9}$ & $2.702 \times 10^{9}$ & $2.931 \times 10^{9}$ & $3.086 \times 10^{9}$ \\
\hline
\end{tabular}


Table 10. Depicting the ship route, vessel speed, fuel consumption and total inventory carried for each problem size of instances 1

\begin{tabular}{|c|c|c|c|c|c|}
\hline Problem size & $\begin{array}{l}\text { Ship } \\
\text { number }\end{array}$ & $\begin{array}{l}\text { Route of the ships } \\
\text { (ports visited by the } \\
\text { ship) }\end{array}$ & $\begin{array}{l}\text { Different vessel } \\
\text { speed of the vessel on } \\
\text { the route (knots) }\end{array}$ & $\begin{array}{c}\text { Fuel consumption on each leg of } \\
\text { the route (Tonnes per Nautical } \\
\text { miles) }\end{array}$ & $\begin{array}{l}\text { Aggregate numbers of } \\
\text { container carried by } \\
\text { each ship on its route } \\
\sum_{p \in P} \sum_{t \in T} \sum_{c \in C} N_{v p c t}\end{array}$ \\
\hline \multirow[t]{2}{*}{$(3,3,2,2)$} & Ship 1 & $1-2-3$ & $20-18$ & $0.29-0.22$ & 1100 \\
\hline & Ship 2 & $1-3-2$ & $18-15$ & $0.22-0.17$ & 1150 \\
\hline \multirow[t]{2}{*}{$(4,4,2,2)$} & Ship 1 & $1-2-4-3$ & $16-22-17$ & $0.18-0.39-0.19$ & 2250 \\
\hline & Ship 2 & $2-1-3-4$ & $15-22-20$ & $0.17-0.39-0.29$ & 2950 \\
\hline \multirow{3}{*}{$(6,5,2,3)$} & Ship 1 & $2-3-1-5-6$ & $22-20-22-15$ & $0.39-0.29-0.39-0.17$ & 3200 \\
\hline & Ship 2 & $1-3-2-6$ & $22-14-19$ & $0.39-0.16-0.25$ & 2733 \\
\hline & Ship 3 & $1-3-2-5$ & $20-16-20$ & $0.29-0.18-0.29$ & 2733 \\
\hline \multirow{4}{*}{$(8,7,2,4)$} & Ship 1 & $1-3-2-4-5-6$ & $16-22-17-16-15$ & $0.18-0.39-0.19-0.18$ & 3900 \\
\hline & Ship 2 & $2-1-3-4-6-8$ & 15-16-22-18-19 & $0.17-0.18-0.39-0.22-0.25$ & 3850 \\
\hline & Ship 3 & $2-1-3-4-8-6-7$ & 20-14-18-14-21-17 & $\begin{array}{c}0.29-0.16-0.22-0.169-0.34 \\
-0.19 \\
\end{array}$ & 4150 \\
\hline & Ship 4 & $4-3-1-2-8-6$ & $16-19-22-14-14$ & $0.18-0.25-0.39-0.16-0.16$ & 3800 \\
\hline \multirow{5}{*}{$(9,10,2,5)$} & Ship 1 & $3-5-1-4-2-9-7-8-6$ & $\begin{array}{l}\text { 14-19-19-19-17-18- } \\
20-21\end{array}$ & $\begin{array}{c}0.16-0.25-0.25-0.25-0.19- \\
0.22-0.29-0.34\end{array}$ & 4880 \\
\hline & Ship 2 & $5-2-4-3-1-6-9-7-8$ & $\begin{array}{c}14-19-20-22-15-17- \\
20-17\end{array}$ & $\begin{array}{c}0.16-0.25-0.29-0.39-0.17- \\
0.19-0.29-0.19\end{array}$ & 4880 \\
\hline & Ship 3 & $4-2-3-1-5-7-9-6$ & $\begin{array}{c}16-15-20-15-21-20- \\
17 \\
\end{array}$ & $\begin{array}{c}0.18-0.17-0.29-0.17-0.34- \\
0.29-0.19 \\
\end{array}$ & 4760 \\
\hline & Ship 4 & $1-5-4-2-3-7-6-8-9$ & $\begin{array}{c}15-16-21-19-16-16- \\
17-22\end{array}$ & $\begin{array}{c}0.17-0.18-0.34-0.25-0.18- \\
0.18-0.19-0.39\end{array}$ & 4800 \\
\hline & Ship 5 & $1-4-2-5-3-9-6-8-7$ & $\begin{array}{c}18-19-20-14-19-14- \\
17-18\end{array}$ & $\begin{array}{c}0.22-0.25-0.29-0.16-0.25- \\
0.16-0.19-0.22 \\
\end{array}$ & 4800 \\
\hline \multirow{6}{*}{$(10,16,2,6)$} & Ship 1 & $4-2-1-3-5-6-10-8-9-7$ & $\begin{array}{c}\text { 19-22-21-16-20-17- } \\
22-14-16\end{array}$ & $\begin{array}{c}0.25-0.39-0.34-0.18-0.29- \\
0.19-0.39-0.16-0.18 \\
\end{array}$ & 5233 \\
\hline & Ship 2 & $1-2-3-5-4-9-6-7-10-8$ & $\begin{array}{c}\text { 14-18-21-20-15-17- } \\
17-18-19 \\
\end{array}$ & $\begin{array}{c}0.16-0.22-0.34-0.29-0.17- \\
0.19-0.19-0.22-0.25\end{array}$ & 5300 \\
\hline & Ship 3 & $1-3-2-4-5-10-7-8-6-9$ & $\begin{array}{c}22-19-15-19-22-21- \\
20-18-16 \\
\end{array}$ & $\begin{array}{c}0.39-0.25-0.17-0.25-0.39- \\
0.34-0.29-0.22-0.18\end{array}$ & 5333 \\
\hline & Ship 4 & $1-2-4-5-3-8-7-10-6-9$ & $\begin{array}{c}\text { 16-16-22-21-21-22- } \\
15-18-19 \\
\end{array}$ & $\begin{array}{c}0.18-0.18-0.39-0.34-0.34- \\
0.39-0.17-0.22-0.25\end{array}$ & 5267 \\
\hline & Ship 5 & $2-1-4-3-5-7-10-8-6-9$ & $\begin{array}{c}\text { 19-17-20-21-19-14- } \\
22-14-18 \\
\end{array}$ & $\begin{array}{c}0.25-0.19-0.29-0.34-0.25- \\
0.16-0.39-0.16-0.22 \\
\end{array}$ & 5130 \\
\hline & Ship 6 & $5-3-1-2-4-6-9-10-8-7$ & $\begin{array}{c}17-21-16-21-20-17- \\
16-16-20\end{array}$ & $\begin{array}{c}0.19-0.34-0.18-0.34-0.29- \\
0.19-0.18-0.18-0.29 \\
\end{array}$ & 5200 \\
\hline \multirow{6}{*}{$(10,22,2,6)$} & Ship 1 & $1-3-4-5-2-10-9-7-6-8$ & $\begin{array}{c}22-20-16-20-15-19- \\
21-22-17 \\
\end{array}$ & $\begin{array}{c}0.39-0.29-0.18-0.29-0.17- \\
0.25-0.34-0.39-0.19\end{array}$ & 6233 \\
\hline & Ship 2 & 5-4-3-2-1-9-6-8-10-7 & $\begin{array}{c}20-20-18-17-16-14- \\
18-15-17 \\
\end{array}$ & $\begin{array}{c}0.29-0.29-0.22-0.19-0.18- \\
0.16-0.22-0.17-0.19 \\
\end{array}$ & 6100 \\
\hline & Ship 3 & $2-1-4-5-3-8-6-7-9-10$ & $\begin{array}{c}18-22-14-22-14-16- \\
21-19-18\end{array}$ & $\begin{array}{c}0.22-0.39-0.16-0.39-0.16- \\
0.18-0.34-0.25-0.22\end{array}$ & 6033 \\
\hline & Ship 4 & $5-4-2-3-1-10-6-8-9-7$ & $\begin{array}{c}15-16-15-16-14-21- \\
22-15-20\end{array}$ & $\begin{array}{c}0.17-0.18-0.17-0.18-0.16- \\
0.34-0.39-0.17-0.29 \\
\end{array}$ & 6100 \\
\hline & Ship 5 & $3-4-2-1-5-7-9-10-6-8$ & $\begin{array}{c}19-20-14-14-15-21- \\
16-18-18\end{array}$ & $\begin{array}{c}0.25-0.29-0.16-0.16-0.17- \\
0.34-0.18-0.22-0.22 \\
\end{array}$ & 6233 \\
\hline & Ship 6 & $1-3-4-2-5-8-6-9-10-7$ & $\begin{array}{c}\text { 16-17-17-22-14-17- } \\
21-19-16\end{array}$ & $\begin{array}{c}0.18-0.19-0.19-0.39-0.16- \\
0.19-0.34-0.25-0.18\end{array}$ & 6033 \\
\hline
\end{tabular}

